\title{
Conversion of geared DC motor into stepper motor using switching delay time signals
}

\author{
Venkatarao Dadi $^{1}$ (D) Swapna Peravali ${ }^{1} \cdot$ Rambabu Busi $^{2}$
}

Received: 7 September 2020 / Accepted: 24 February 2021 / Published online: 20 March 2021

(c) The Author(s) 2021, corrected publication 2021 OPEN

\begin{abstract}
In solar tracking system, general stepper motor is used to control the stepwise movement and low speed of solar panel in vertical motion. Degree of rotation is directly proportional to stepwise movement (stepping method) of stepper motor. But it is cumbersome process to hold a solar panel at a particular vertical position depending on the sun's position using low cost stepper motors. So, geared DC motor is implemented into stepper motor for low-speed applications using Stepping Method (GDCSM). Degree per step movement of geared DC motor is identified using Step angle switching delay time signal (A) of microcontroller. Speed of geared DC motor is controlled by passing fixed time interval between the pulses where the pulses have fixed width. Controlling speed is implemented by using Step delay time signal (D) of microcontroller. Combining effect of switching delay time signals $\boldsymbol{A}$ and $\boldsymbol{D}$ represents the Stepping Method. Stepping method resembles the step movement and controlling speed of the stepper motor. Speed of 10RPM \& 30RPM geared DC motors is operated at 10V DC power supply. Microcontroller ATmega 328P with switching delay time signals is used to control the geared DC motors. Performance of 10RPM \& 30RPM GDCSM is analyzed with stepper motors in terms of Relative slip degree error per revolution ( $\left(\mathrm{RE}_{\mathrm{S}}\right)$ and acceptable slippage degree tolerance under open loop condition. Change in consuming voltage tolerance $(\Delta)$ during rotation of GDCSM is another parameter which is used to maintain the constant actual total step count per revolutions of GDCSM. At $40 \mathrm{~ms}$ of step angle delay time (A), 10RPMGDCSM has 120 steps per revolution. At $25 \mathrm{~ms}$ of $\boldsymbol{A}, 30 \mathrm{RPMGDCSM}$ has 55 steps per revolution. Speed of 10RPM \& 30RPM GDCSM is controllable up to $2 \mathrm{RPM}$ when its $\mathbf{R E}_{\mathrm{S}}$ or acceptable slippage degree tolerance value is less than or equal to $1 \%$. If $\Delta$ value of GDCSM is less than or equal to $-0.4 \%$, then it behaves like stepper motor. GDCSM is suitable to hold and control vertical position of solar tracking system with low speed and step movement. Performance of geared DC motor experimentally showed better result than commercial available stepper motors like 28BYJ-48 or STP-43d1027-01.
\end{abstract}

Keywords Switching delay time signals - Step angle delay time - Step delay time - Relative slip degree error per revolution. Geared DC motor

\section{Introduction}

Stepper motor is controlled with two control parameters such as Step angle and Delay time between steps which are instructed by microcontroller. Step angle (i.e., constant angular position) depends on total number of steps per revolution. Speed of stepper motor depends on the delay time between the steps.

In open loop, stepper motor converts a train of input pulses into a precisely defined increment in the shaft position. Each pulse moves the shaft through a fixed angle.

\footnotetext{
$\triangle$ Venkatarao Dadi, dadivenkatarao@gmail.com; Swapna Peravali, peravali_r2000@yahoo.co.in; Rambabu Busi, rams1315@gmail.com | 'Department of Instrument Technology, A.U.C.E(A), Andhra University, Visakhapatnam, Andhra Pradesh 530003, India. ${ }^{2}$ Electronic Instrumentation, Lakireddy Bali Reddy College of Engineering, Krishna District, Mylavaram, Andhra Pradesh 521230, India.
} 
The motor shaft turns stepwise with an integer number of steps making a full rotation.

A unipolar stepper motor has one winding with center tapped phase. Each section of winding is switched on for each direction of magnetic field. A magnetic pole can be reversed without switching the direction of current. Bipolar stepper motors have a single winding per phase. The current in a winding needs to be reversed in order to reverse a magnetic pole. Viaene Jasper [1] discussed characteristics of stepper motor and its step movement under open loop condition. Stepping motor driver excites rotor over a predefined discrete angular position. Main feature of stepper motor is easy control like start, stop, forward and reverse directions. It has self-locking function. Speed can be varied with a wide range of smooth adjustment.

Speed of the DC motor is directly controlled by applied voltage of the motor in Input voltage control method. The average value of the applied motor voltage is varied by applying a pulse width modulated (PWM) waveform to the motor. The pulse width can be adjusted by the controlled program or comparator circuits. The flux of the permanent magnet stator is constant in permanent magnet $D C$ (PMDC) motor, field control method is not used in PMDC motors, and the speed of the motor changes solely with the back induced armature e.m.f.

The average voltage and current fed to the load are controlled by switching ON and OFF between supply and load at a fast pace. When the DC motor is on, it takes certain time to reach at full speed. Then, the power source is ON, the DC motor starts gaining speed and if switched OFF, the power source goes down before reaching the rated speed, it starts to goes down. When switching ON and OFF are done quickly, the motor rotates at a lower speed between zero and rated speed.

Authors [2, 3] used the various DC motor drivers to control the power supply of DC motor using microcontroller under open loop conditions. [2] Anjaly Divakar controls the power supply of DC motor with L293D motor driver using switching duty cycle. [3] Hameed drives mechanical relays for changing the timing resistors of an astable multivibrator. Relays are constructed by 2N222 transistors. Power supply of DC motor is controlled the relay switch ON and OFF for three different speed levels. Operated the DC motor at $10 \mathrm{~V}$ supply under no load condition. Authors [4-6] controlled the power supply of DC motor using various motor drivers and micro-controller or micro-processor with closed loop system. [4] Khan and Kamil controlled the supply of DC motor with L293D IC driving the motor which is made up of two H-Bridge. [5] Ali Hassan controlled the supply voltage of PMDC with IBT-2 driver. [6] SSyukriyadin controlled power supply of PMDC motor by motor drive module BTS7960 using PWM signal. It has a fixed frequency of waves with varying duty cycles.
From the literature [2-6] it is analyzed that for very low speed applications DC motors are unable to utilize in open loop and closed conditions. DC motors speed is changed by varying the power supply. Also, not discussed holding a particular vertical position (i.e., angular position) when DC motors are used in vertical rotating tracking applications.

DC motor's shaft speed is reduced by coupling geared system to the motor shaft. Geared system also increases the torque output of the motor. [7] Vitor designed motor coupled with worm geared system used as speed reducers in low- to medium-speed application. This design is mainly used in a robotic application, when the arm's joint reaches a desired angle, it does not move until a next signal is given. [8] T. Verstraten implemented a simple energy efficient simple actuator in mechatronic designs with DC motor and gearbox. [9] Wenyu explained dynamic electromechanical characteristics of the motor-planetary gear system under voltage transients. [10] Sanjai designed optimized gear ratios which plays a crucial role in the loading and efficiency of the motor, thus affecting the battery mileage in hybrid electric vehicle.

DC motors with geared system also used to control angular position of shaft. [11] Aravind controlled the DC motor angular position with backlash setup using Experience Mapping based Predictive Controller (EMPC) technique. In robotic applications angular position of geared DC motor is controlled using closed loop mechanism. [12] Myo Maung designed precision of angular position control for 120RPM geared DC motor using PID controller with compensation of friction effect. [13] Hannibal Paul proposed the angular position control of 45RPM geared DC motor with gear reduction condition.

Swathi [14] designed cost effective and reliable Electrical vehicle suitable for linear agricultural applications using Servo and Geared DC motors. [15] Seungjae designed the motor torque distribution between the two motors coupled with two-speed powertrain system. Powertrain system consists of first and second gear ratios. The torque from the motor output shaft is transferred to the wheels for driving the vehicle. This optimized system improves both performance and energy efficiency. [16] Amol designed electrochemical-based rain sensing wiper system coupled to geared DC motor which is independent in operation of the micro-controller of the vehicle. The geared DC motor consumes almost $10 \%$ less current than the conventional wiper Lucas motor system.

Al-Jarrah [17] discussed the dynamic performance of the four-bar mechanism driven by a geared DC motor under different operating conditions using different control schemes. Four-bar mechanism is used in the wheels of rail engine, pantograph and pumpjack applications. [18] Tutunji explained the linear parametric and neural networks models of four-bar linkage mechanism which is 
driven by geared DC motor. [19] Ali designed a walking ability system using geared DC motor for stroke patients to train the effected leg and regain walking ability. [20] Frankovsky implemented two-wheeled self-balancing robot driven by the geared DC motors which are used as the actuator subsystem of the robot. [21] Lee proposed bilateral teleportation control system of two link planar manipulators using geared DC-motors. Manipulators are actuated by geared DC motor attached to planetary gear head to increase the output torque.

[22] Venkataro and Swapna Pervali designed dual axis solar tracking system (DAST) application in which vertical movement of DAST system is operated by 10RPM geared DC motor. Motor is controlled with switching delay time signals. Delay time signals with low time interval mechanism can provide constant low speed. Speed of 10RPM geared DC motor depends on optimized intensity of light measured by light dependent resistors (LDR). Feedback network contains LDR segment.

Geared DC motors are used in control systems where an appreciable amount of shaft power is needed [23]. Geared DC motors have low inertia, symmetrical rotation and smooth low-speed characteristics. Geared DC motors are used in automation, robotics, industrial machines and medical sciences. The advantage of geared DC motor is ability to produce high torque so that the size of the motor is less compared to the size of the stepper motors.

In dual axis low-speed solar tracking applications, tracking depends on the degree of motors rotation. Stepper motor is used to drive the elevated (vertical) position. Geared DC motor holds a particular vertical (elevated) angular position of solar panel in sun position tracking applications. Precise angular position depends on the step movement (i.e., degree/step) of geared DC motor. Practically identified that fixed degree per step is changed with the change in tolerance of supply voltage.

A new method is proposed such that geared DC motor behaves like stepper motor which is analyzed under open loop and no load condition. Step movement (degree per step) of geared DC motor using switching delay time signals from microcontroller which are designed based on operating instructions like Step angle and Speed of stepper motor. Supply of geared DC motor driver is connected with Constant voltage and Constant current source with minimum change in tolerance, so that degree per step is fixed during rotation of geared DC motor.

Two major switching delay time signals implemented with delay time signals of microcontroller are: step angle delay time $(\boldsymbol{A})$ of geared DC motor which works like fixed step movement (or angular position change) of stepper motor, Step delay time (speed delay time) (D) of geared DC motor which works like speed control mechanism of the stepper motor. This method is called Stepping method which resembles the stepper motor operation.

Short comings are:

1. From the literature of closed or open loop DC motor speed control techniques, switching between $\mathrm{ON}$ and OFF digital signals implemented with constant delay time intervals using microcontroller controls the speed and angular position of the geared DC motor. Identified that if Relative slip degree error per revolution ( $\mathbf{R E}{ }_{\mathrm{S}}$ ) of geared DC motor is minimized using Stepping method, then it works like stepper motor.

2. Calibration of actual step count per revolution of GDCSM with different values of step angle delay time (A).

3. Experimentally identified that change in tolerance values of consumed voltage $(\Delta)$ leads to change in actual step count per revolution, which causes the slip degree error per revolution for GDCSM. Minimization of slip degree error per revolution is possible by controlling minimum range of $\Delta$ which is achieved by passing maximum current to $\mathbf{G D C S M}$.

Implementation of stepping method with two switching delay time control parameters is discussed in sect. 2.1. Identification process of actual step count per revolution of GDCSM is discussed in sect. 2.2 as shown in Fig. 1. Discussed the 10RPM GDCSM in sect. 2.3. Analysis of step angle delay time $(A)$ of GDCSM with minimum value of $R E$ ${ }_{S}$ is discussed in section 2.4.

Stepper motors like 28byj-48, STP-43d1027-01 at various operating supply conditions and their corresponding values of $\mathbf{R E}_{\mathrm{s}}$ are discussed in sect. 2.5.

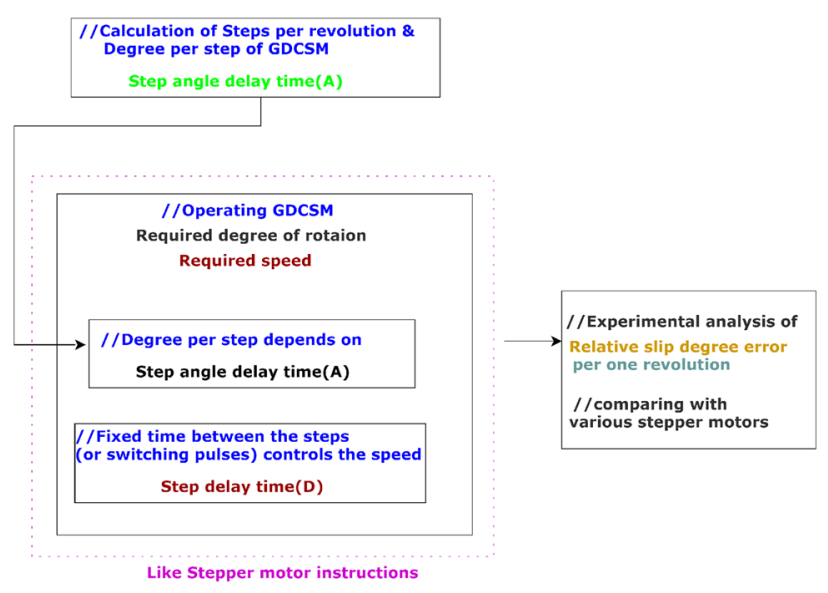

Fig. 1 Proposed work 


\section{Methodology}

\subsection{Design of switching delay time mechanism to control Step angle delay time $(A)$, Step delay time (D):}

Switching between $\mathbf{O N}$ and $\boldsymbol{O F F}$ of the supply voltage of geared DC motor along with fixed switching delay time interval is implemented with Delay time signals of microcontroller which operates geared DC motor like stepper motor. Delay time signal is the key element to control the parameters like angular position (step angle) and speed of the geared DC motor using microcontroller. Pausing the microcontroller operation is done by Delay time signal. To operate geared DC motor into stepper motor has three stages of control conditions such that initialization, step angle delay time $(A)$, and step delay time $(D)$ as shown in Fig. 2.

Initialization stage starts with a delay time of instruction of $10 \mu \mathrm{s}$ which is followed with direction condition instruction. Motor direction is controlled by direction instruction. The direction of motor is controlled by digital signals from microcontroller. Motor driver module is interfaced between DC power supply and motor power lines (or input lines) like In_1 or In_2. In_1 or In_2 are controlled by digitally High (i.e., switch $\mathbf{O N}$ ) or Low (i.e., switch OFF) signals which are given to driver from microcontroller.
Switched to $\mathbf{O N}$ condition of any one of input control line (In_1 or In_2) and another input line is switched to OFF condition using controller which changes the direction of geared DC motor either clock wise (CW) or anti clockwise (ACW). After switched to $\mathbf{O N}$ state of one input line geared DC motors changes it shaft position and controller comes to pause state immediately using delay time signal of interval of $900 \mu \mathrm{s}$ (micro-seconds) in initial stage. This process of initialization is given for each step movement of geared DC motor before each step angle delay time $(A)$ stage. Step angle delay time $(\boldsymbol{A})$ is switching delay time signal which follows the initialization stage immediately. Step angle delay time (A) stage pauses the controller additionally by some time using delay time signal of interval of $\boldsymbol{A}$ ms (milliseconds) which controls change in the step angle (i.e., Angular position) along with immediate digital OFF signals given to all input control lines of geared DC motor. Constant step angle change depends on the value of $\boldsymbol{A}$. Step delay time (D) is switching delay time signal which follows the Step angle delay time (A) stage. Step delay time $(D)$ is immediately paused giving the controller some more interval time of $\boldsymbol{D} \mu \mathrm{s}$. Delay time signal of $\boldsymbol{D}$ $\mu \mathrm{s}$ is introduced between each step movement so that it controls the speed of the geared DC motor. $\boldsymbol{D}$ depends on Steps per Revolution and Revolutions per minute (RPM). Geared DC motors implemented with stepping method (GDCSM) behave like stepper motors.

GDCSM clokc wise direction

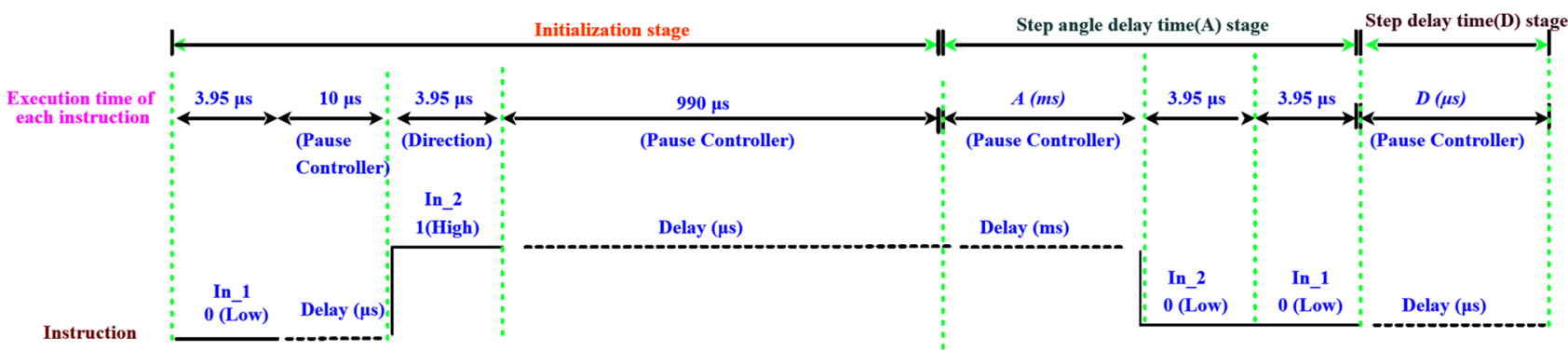

GDCSM anti clock wise direction

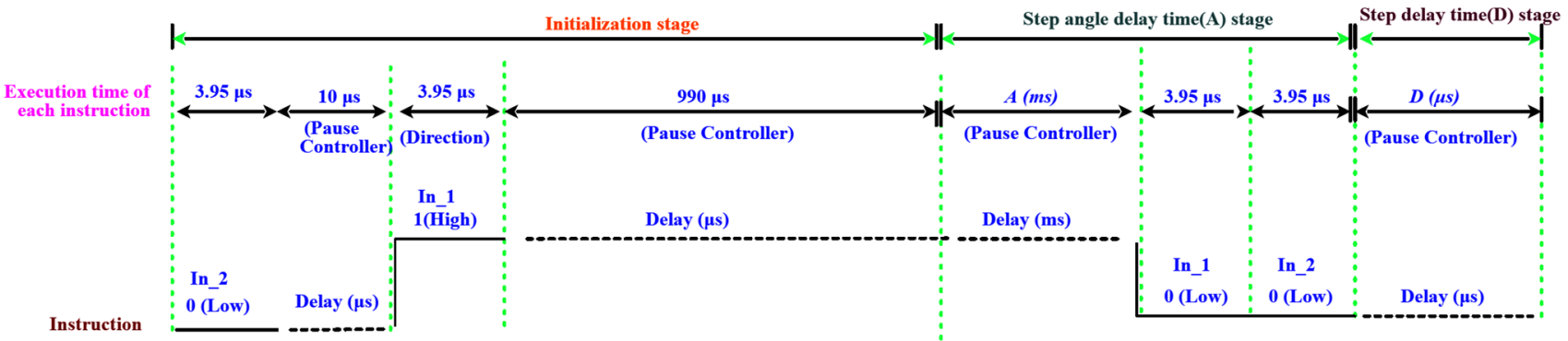

Fig. 2 Switching delay time signals 


\subsection{Counting actual steps per revolution}

Actual Steps per Revolution are calibrated for 10RPM or 30RPM GDCSM separately as shown in Fig. 3. They are interfaced by motor driver module L293D. Operated with constant $D C$ supply voltage and controlled with minimum value of $\Delta$ using $\mathbf{C V} \& C C$ module.

For different values of step angle delay time (A), actual Steps per Revolution of 10RPM GDCSM or 30RPM GDCSM is calibrated at speed of 1RPM as shown in Fig. 4. Initially assumed that 500 Steps per Revolution at 1RPM. $120,000 \mu$ s of Step delay time (D) is passed between steps which is calculated using Eq. (1). Counting of steps is observed either by tic sound or step movement by eye contact. Calibration of actual Steps per Revolution is independent of value of $\boldsymbol{D}$, whereas value of $\boldsymbol{D}$ depends on the actual Steps per Revolution (Fig. 5).

$D(\mu s)=\frac{60000000}{\left(\frac{\text { Steps }}{\text { Revolution }}\right) / \text { RPM }}$

$\boldsymbol{A}$ is changed from 0 to $40 \mathrm{~ms}$ and carefully measured values of actual Steps per Revolution for each value of $\boldsymbol{A}$.

We observed that at different time sessions actual Steps per Revolution is changed even when value of $\boldsymbol{A}$ is constant and constant voltage (CV) is applied to geared DC motors. This is due to large value of $\Delta$ effect during rotation of motors as speed of the geared DC motor is changed with change in voltage. Large value of $\Delta$ effect during rotational condition of motor is minimized by keeping the maximum current supply to motors using constant current (CC) source. Set to maximum constant current

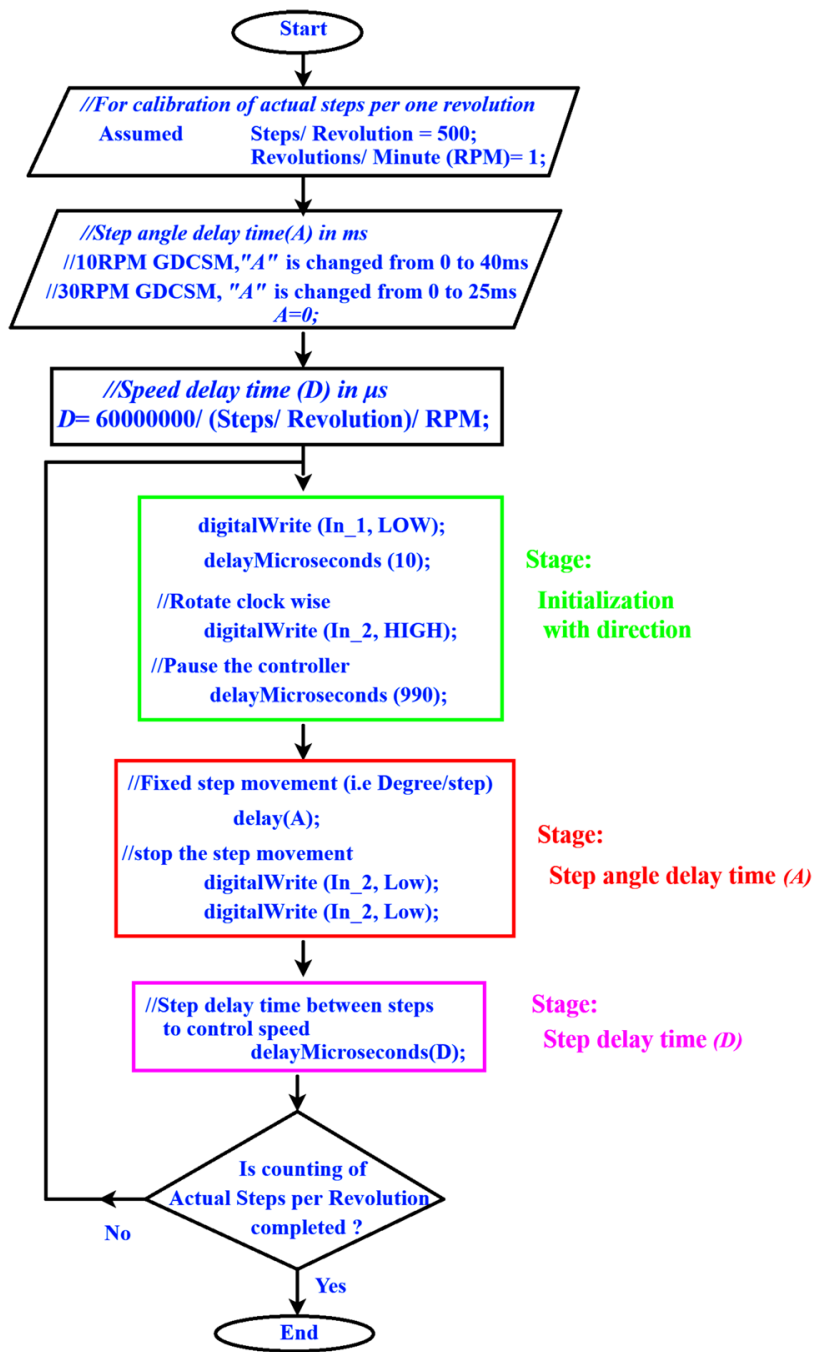

Fig. 4 Counting actual steps per revolution
Fig. 3 i.LM2596 CC\&CV bucker, ii. Motor driver L293D, iii.10RPM geared DC motor, iv.30RPM geared DC motor

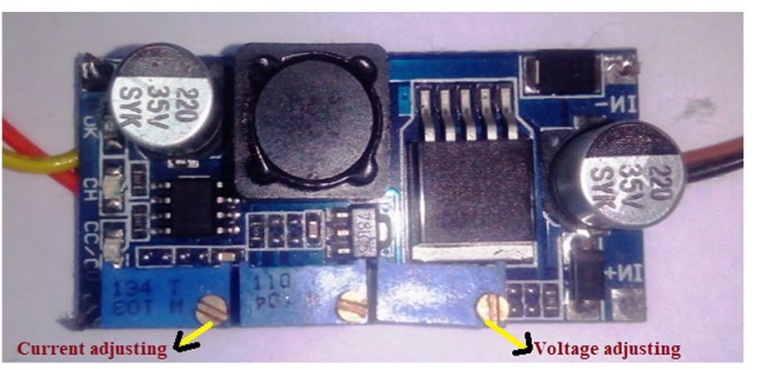

i. LM2596 1.25V to 35V step down Buck Constant Voltage/Constant Current (CV/CC) DC-DC converter

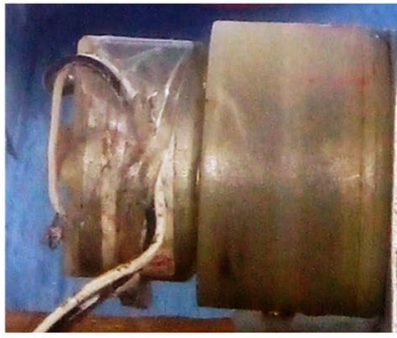

iii. 10 RPM geared DC motor

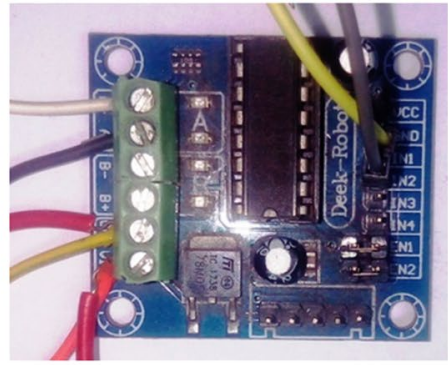

ii. Motor driver L293D module
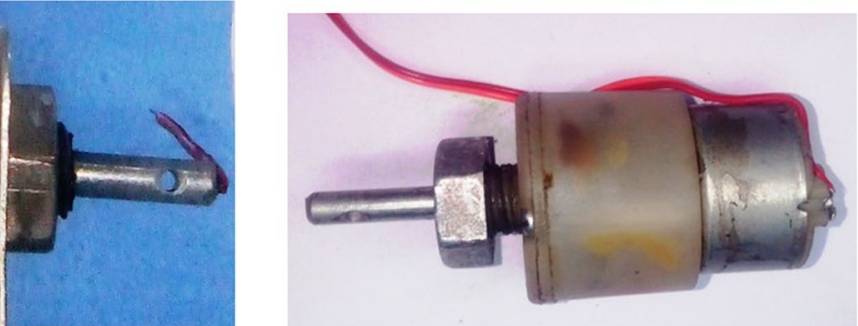

iv. $30 \mathrm{RPM}$ geared $\mathrm{DC}$ motor

SN Applied Sciences A SPRINGER NATURE journa 


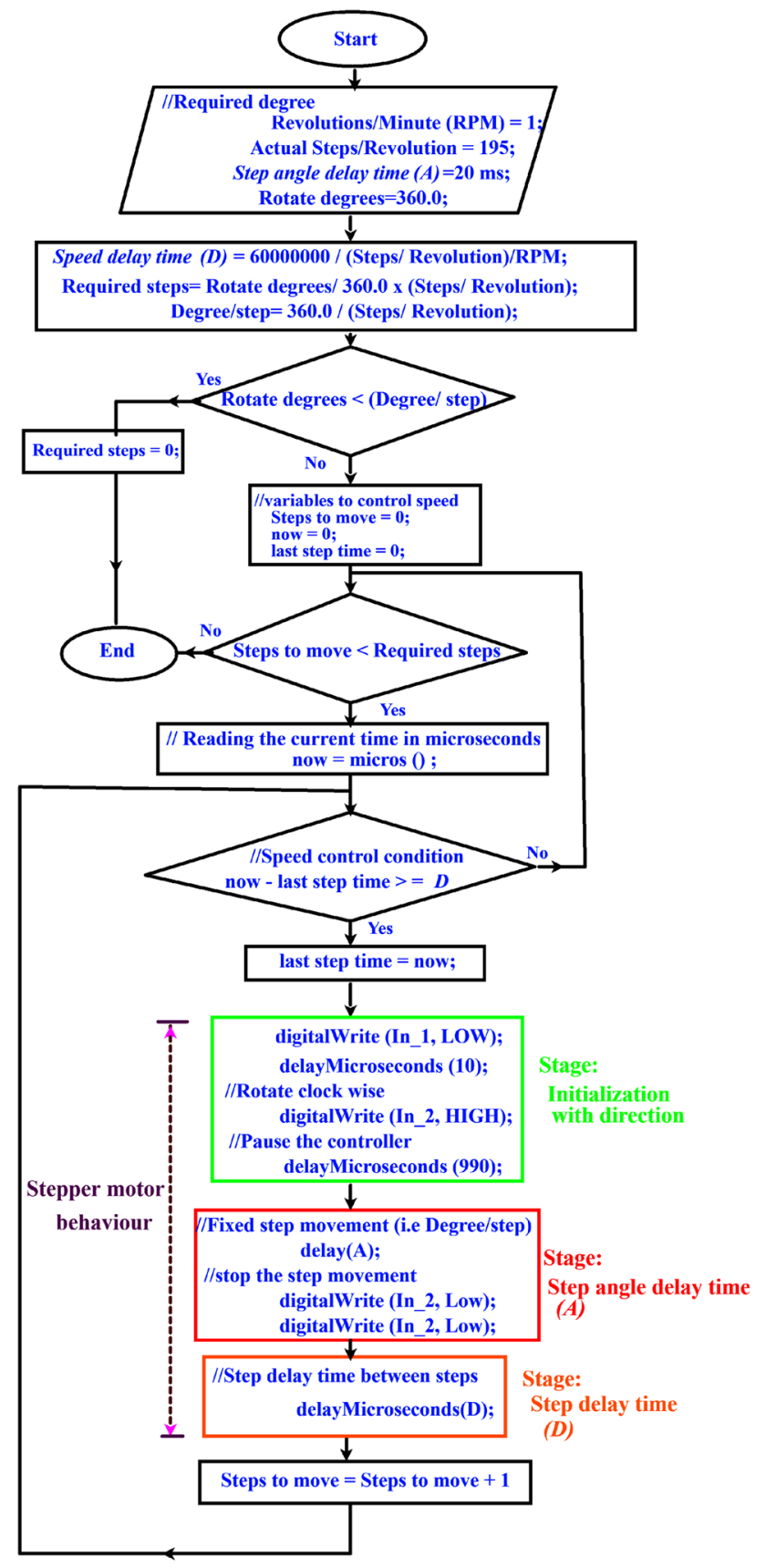

Fig. 5 10RPM GDCSM flow chart

using CC module keeps the value of $\Delta$ below $-0.4 \%$ during rotational of GDCSM.

\subsection{RPM GDCSM operated per one revolution}

CC\&CV module is interfaced between $12 \mathrm{~V} \mathrm{DC}$ power supply and supply terminals of motor driver L293D module. Supply voltage is stepped down to $10 \mathrm{~V}+0.1 \%$ using CV. $-0.29 \%$ of $\Delta$ is maintained using CC for 10RPM GDCSM. As slippage degree error is calibrated per one revolution so required rotate degrees are considered as $360^{\circ}$ as shown in Fig. 4. Step delay time (D) controls the speed of geared DC motor which is set to 1RPM. $D$ is a switching time parameter which is inserted between each fixed step angle position. Constant angular position (i.e., step movement) change is controlled by Step angle delay time (A) which is another switching time parameter. Actual Steps per Revolution is 195 for 10RPM GDCSM at 20 ms of $\boldsymbol{A}$ which is calibrated using initial calibration method as shown in Fig. 4. Degree per step and $\boldsymbol{D}$ are calculated from steps per revolution. Difference of present step time to last step time is measured using microsecond function of Arduino ATmega 328P microcontroller which has clock speed of $16 \mathrm{MHz}$. Number of microseconds are returned when Arduino board starts running the instruction of current microseconds function. If value of $\boldsymbol{D}$ is greater than or equal to difference of present step to last step time, then switching delay time interval of $\boldsymbol{D}(\mu \boldsymbol{s})$ is passed between the steps to control the speed of GDCSM. 10RPM GDCSM has the following stages of conversion process: Initialization stage controls direction and provides initial minimum acceleration for step movement of GDCSM. Step angle delay time $(A)$ stage controls constant angular position of shaft movement at $20 \mathrm{~ms}$ of step angle delay time signal. Step delay time $(D)$ stage controls the speed of geared DC motor with $307692 \mu$ s (i.e., 1RPM) of speed delay time signal.

\subsection{Relative slip degree error per revolution}

In general stepper motors Steps per Revolution is fixed at rated voltage. They have fixed Degree per step. In GDCSM, for each value of $A$ for 10RPM GDCSM, 30RPM GDCSM they have different value of actual Steps per Revolution. Minimum value of Relative slip degree per revolution (RE $\left.{ }_{S}\right)$ in terms of degree helps to identify which value of $\boldsymbol{A}$ of GDCSM to be taken to behave like stepper motor. Experimentally measured $\mathbf{R E}_{\mathrm{s}}$ values of general stepper motors models (i.e., discussed in supplementary Sect. 2.5) are taken to identify the suitable value of $\boldsymbol{A}$ of GDCSM so that it works like stepper motor. Slippage degree per revolution is difference of Measured degree per one revolution $\left(\boldsymbol{M}_{\mathrm{D}}\right)$ to one revolution (i.e., exactly $360^{\circ}$ ) using Eq. (2). It is used to calculate $\mathbf{R E}_{\mathrm{S}}$ of the geared $D C$ motors at different values of $\boldsymbol{A}$ using Eq. (3).

$\frac{\text { Slippage degree }}{\text { Revolution }}=M_{D}-360^{\circ}$

$\mathrm{RE}_{\mathrm{S}}=\frac{\left|\frac{\text { Slippage degree }}{\text { Revolution }}\right|}{360} \times 100 \%$ 
here experimentally measured $\mathbf{R E}_{\mathrm{S}}$ value of stepper motor models like I, III \& V are considered for identification of $\boldsymbol{A}$ of GDCSM. Models I, III \& V are used generally in applications at operating condition of direct power supply (without CV \& CC modules). RE $_{\mathrm{s}}$ value of stepper motor models like I, III \& V is greater than the models II\&IV which are controlled with CV \& CC modules. CV\&CC modules interconnected with power supply also reduce the $\mathbf{R E}_{\mathbf{S}}$ value of stepper motors so that GDCSM controlled with CV\&CC modules also minimizes the value of $\mathbf{R} \mathbf{E}_{\mathrm{s}}$.

If $\mathrm{RE}_{\mathrm{S}}$ of GDCSM at a selected step angle delay time $(\boldsymbol{A})$ is less than or equal to $\mathbf{R E}_{\mathbf{S}}$ value of stepper motor models like I or III or V, which means GDCSM can be operated as stepper motor at that particular selected value of $\boldsymbol{A}$.

\subsection{Supplementary information}

\section{Stepper motors operated with different supply conditions}

Generally direct power (without CV\&CC module) supply is applied to stepper motor through driver using DC power supply adapter as shown in Fig. 6 . Required change in angle and speed is controlled using control signals from ATmega 328P microcontroller which are discussed in model I, III\&V. Their corresponding measured values of Total degree change per revolution and $\mathrm{RE}_{\mathrm{S}}$ of stepper motors for one revolution under open loop conditions are shown in Table 1. Calculation of $\Delta$ value is considered at maximum value of consuming voltage $\left(V_{C}\right)$ which is measured during their rotation.

Model I Unipolar stepper motor 28byj-48 with motor driver ULN2003A is operated at rated DC supply voltage $\left(\mathrm{V}_{\mathrm{S}}\right)$ of $5 \mathrm{~V}+0.2 \%$ (i.e., 5 to $5.01 \mathrm{~V}$ ) using $\mathrm{DC}$ to $\mathrm{DC}$ step down voltage bucker. During its horizontal movement $(\mathrm{H})$, maximum value of $\mathrm{V}_{\mathrm{C}}$ is $4.94 \mathrm{~V}$ with $-0.4 \%$ of $\Delta$ (i.e., 4.92 to $4.94 \mathrm{~V}$ ) and its corresponding value of $\mathrm{RE}_{\mathrm{S}}$ is $0.7 \%$. During its vertical movement $(\mathrm{V})$, maximum value of $\mathrm{V}_{\mathrm{C}}$ is $4.93 \mathrm{~V}$ with $-0.4 \%$ of $\Delta$ (i.e., 4.91 to $4.93 \mathrm{~V}$ ) and its corresponding value of $\mathrm{RE}_{\mathrm{S}}$ is $0.6 \%$.

Model III Bipolar stepper motor STP-43d1027-01 with motor driver L293D is operated with rated $12 \mathrm{~V} \mathrm{DC}$ adapter which gives actual supply voltage $\left(\mathrm{V}_{\mathrm{S}}\right)$ of $12 \mathrm{~V}-2 \%$ (i.e., 11.76 to $11.77 \mathrm{~V}$ ). During its horizontal movement, maximum value of $V_{C}$ is $9.09 \mathrm{~V}$ with $-66.77 \%$ of $\Delta$ (i.e., 3.02 to $9.09 \mathrm{~V})$. Its corresponding value of $R E_{S}$ is $0.3 \%$. During its vertical movement, maximum value of $\mathrm{V}_{C}$ is $9.27 \mathrm{~V}$ with $66.09 \%$ of $\Delta$ (i.e., 3.05 to $9.27 \mathrm{~V}$ ). Its corresponding value of $R E_{S}$ is $0.3 \%$. In this case $R E_{S}$ is not affected even there is a large change in value of $\Delta$. Minimum value of $\Delta$ cannot be maintained by using L293D driver module under direct supply of voltage without CC\&CV modules.

Model V Bipolar stepper motor STP-43d1027-01 with $H$ Bridge motor driver L293N. It's operated with $12 \mathrm{~V}$ DC adapter which gives actual supply voltage of $12 \mathrm{~V}-2 \%$ (i.e., 11.76 to $11.77 \mathrm{~V}$ ). During its horizontal or vertical movement, maximum value of $\mathrm{V}_{C}$ is $11.77 \mathrm{~V}$ with $-0.08 \%$ of $\Delta$ (i.e., 11.76 to $11.77 \mathrm{~V}$ ) and its corresponding value of $\mathrm{RE}_{\mathrm{S}}$ is $0.3 \%$. During its vertical movement, it has $0.1 \%$ of $\mathrm{RE}_{\mathrm{S}}$.

Observed that Model I, III \& V are also able to operate at higher RPMs. There is no speed synchronization problem when speed is greater than 1RPM. At higher value of RPM, value of $R E_{S S}$ is negligible and equals to values of $R E_{S}$ at 1RPM of Model I or III or V.

During horizontal rotation, Model $\mathrm{V}$ has $0.3 \%$ of $\mathrm{RE}_{\mathrm{S}}$ and Model I has $0.7 \%$ of $\mathrm{RE}_{\mathrm{s}}$. During vertical rotation, Model
Fig. 6 i. STP-43d1027-01 bipolar stepper motor, ii. Motor driver L293N, iii. Motor driver L293D, iv. 28byj-48 unipolar stepper motor

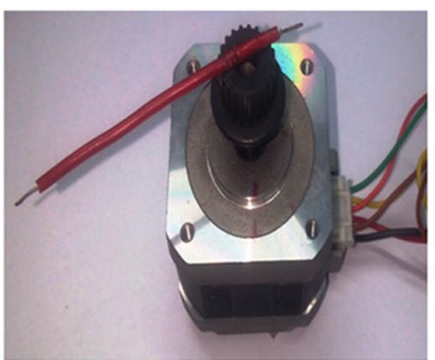

i. STP-43d1027-01 Bipolar Stepper motor

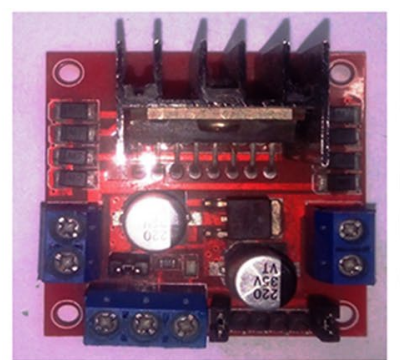

ii. Driver L293N (H bridge)

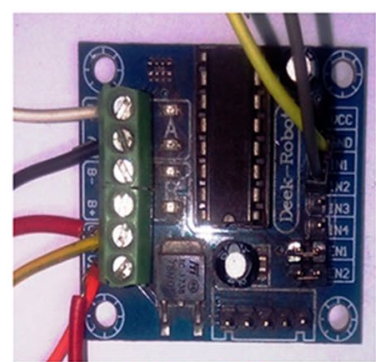

iii. Driver L293D

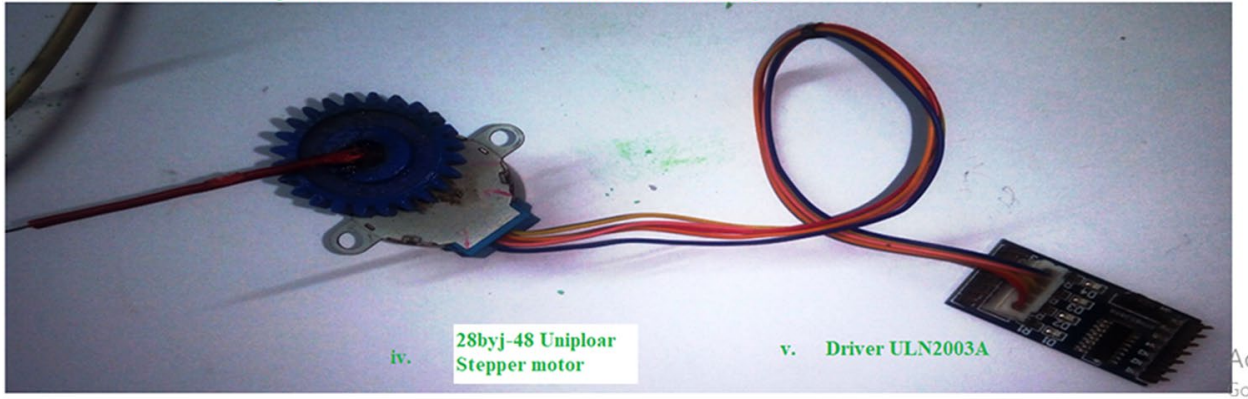

SN Applied Sciences A SPRINGer NATURE journal 


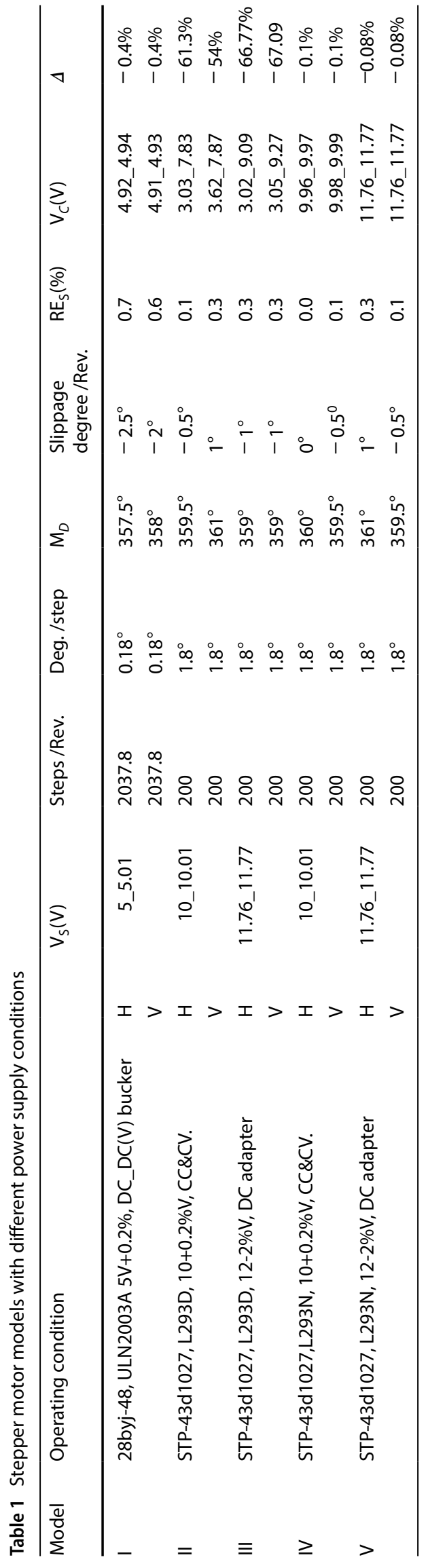

$V$ has $0.1 \%$ of $\mathrm{RE}_{\mathrm{S}}$ and Model I has $0.6 \%$ of RES. Analyzed that values of $\mathrm{V}_{C}$ are changed with minimum value of $\Delta$ in model $V$ is due to $H$ Bridge, whereas minimum value of $\Delta$ in model I is due to driver ULN2003A. H Bridge itself provides maximum constant current and constant voltage for stepper motors. $\mathrm{RE}_{\mathrm{S}}$ values of Model I, III \& V are taken as reference values to analyze the actual step angle delay time (A) of GDCSM for different mode of operation.

Proposed work is tested on 10RPM, 30RPM geared $\mathrm{DC}$ motors and values of $\mathrm{V}_{\mathrm{S}}$ are set to $10 \mathrm{~V}+0.1 \%$. Using CV\&CC module, maximum position of CC is applied to minimize value of $\Delta$. CV \& CC module controls the operating power supply of stepper models like II \& IV. Their corresponding values of $R E_{S}$ are also analyzed at operating $D C$ supply condition of $10 \mathrm{~V}+0.1 \%$ of $\mathrm{V}_{\mathrm{S}}$ (i.e., 10 to $10.01 \mathrm{~V}$ ) with maximum position of $\mathrm{CC}$.

Model II Bipolar stepper motor STP-43d1027-01 interconnected with motor driver L293D. It has maximum value of $\mathrm{V}_{\mathrm{S}}$ is $7.83 \mathrm{~V}$ with $-61.30 \%$ of $\Delta$ (i.e., 3.03 to $7.83 \mathrm{~V}$ ) during its horizontal rotation. Its corresponding value of $\mathrm{RE}_{\mathrm{s}}$ is $0.1 \%$. During its vertical movement, it has maximum value of $\mathrm{V}_{C}$ which is $7.87 \mathrm{~V}$ with $-54 \%$ of $\Delta$ (i.e., 3.62 to $7.87 \mathrm{~V}$ ). Its corresponding value of $\mathrm{RE}_{\mathrm{S}}$ is $0.3 \%$. Stepper motor model II able to operate at 1RPM only without any disturbance of step movement and unable to operate when RPM is greater than 1RPM. This is because insufficient supply voltage causes the disturbance of step movement. Driver L293D module not able to control minimum value of $\Delta$.

Model IV Bipolar stepper motor STP-43d1027-01 interconnected with $H$ Bridge motor driver L293N. Its maximum value of $\mathrm{V}_{C}$ is $9.97 \mathrm{~V}$ with $-0.1 \%$ of $\Delta$ (i.e., 9.96 to $9.97 \mathrm{~V}$ ) during its horizontal or vertical rotation. Its horizontal rotation has $0.0 \%$ of $\mathrm{RE}_{\mathrm{s}}$. Its vertical movement has $0.1 \%$ of $\mathrm{RE}_{\mathrm{s}}$. Stepper motor model IV is able to operate without any disturbance of step movement up to 5 RPM only.

Stepper motor models II \& IV are controlled with CV\&CC module. They have very less $\mathbf{R E}_{\mathrm{S}}$ values compared with model I. But unable to operate models II \& IV without any disturbance of step movement with increased RPM.

\section{Experimental setup}

RE $_{\mathrm{S}}$ of 10RPM or 30RPM GDCSM is measured when motors are operated in horizontal or vertical movement as shown in Figs. 7 and 8. Change in consuming voltage tolerance ( $\Delta$ ) of GDCSM plays the major key role to control the actual Steps per Revolution is constant if there is a large change in value of $\Delta$ which leads to change in calibrated value of actual Steps per Revolution. Further it leads to more or less than the required change in angular position (i.e., step movement) of GDCSM even the angular position which is operated with constant value 


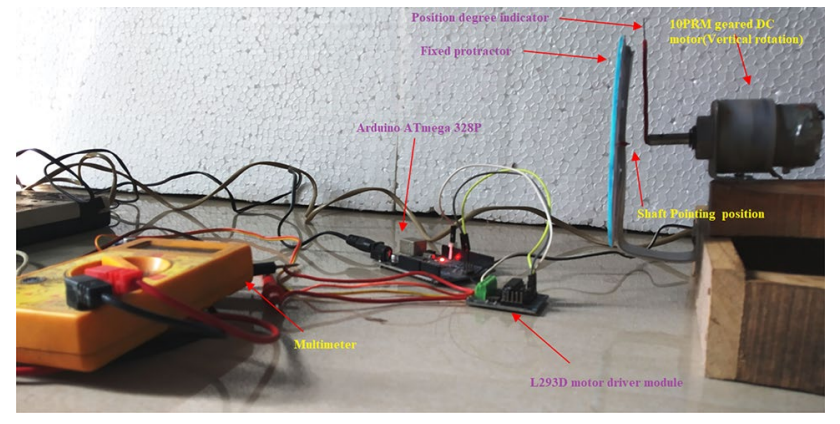

Fig. 7 10RPM GDCSM horizontal rotation

of $\boldsymbol{A}$. This is because of variation in consuming voltage of GDCSM which causes the speed synchronization problem.

LM2596 is DC to DC step down Buck converter module provides Constant Voltage and Constant Current (CV\&CC). Its range of voltage conversion is 1.25 to $35 \mathrm{~V}$. LM2596 is connected between 12 V DC adapter and supply terminals of L293D motor driver module as shown in fig. Supply voltage $\left(\mathbf{V}_{\mathbf{S}}\right)$ is adjusted to $10 \mathrm{~V}+0.1 \%$ (i.e., 10 to $10.01 \mathrm{~V}$ ) and their corresponding voltages are observed in digital multimeter. The speed of 10RPM geared DC motor at operating supply of $10 \mathrm{~V}+0.1 \%$ is $11.6 \mathrm{RPM}$ and it has $0.028 \mathrm{~A}$ of consumption of current during its rotation. The rotational speed of 30RPM geared DC motor with supply value of $10 \mathrm{~V}+0.1 \%$ is $29 \mathrm{RPM}$ and it has consumption of current of $0.039 \mathrm{~A}$. Supply voltage is set to $10 \mathrm{~V}+0.1 \%$ because the $12 \mathrm{~V} \mathrm{DC}$ adapter has $98 \%$ efficiency level so that it gives the range of output voltage of 11.75 to $11.76 \mathrm{~V}$. The results are analyzed for 10 \& 30RPM GDCSM at operating supply voltage of $10 \mathrm{~V}+0.1 \%$. During rotation of GDCSM, value of $\Delta$ is controlled below $-0.4 \%$. This is done by adjusting maximum position of CC of LM $2596 \mathrm{CV} / \mathrm{CC}$ module. Adjusting to maximum position of $\mathrm{CC}$ means keeping the minimum value of $\Delta$ and it is observed in multi meter in terms of change in $\mathbf{V}_{C}$. Power supply to microcontroller ATmega 328P is provided by 9V DC adapter. Control signals are passed to L293D motor driver module which is interface between microcontroller and geared DC motors. Gear box must not exceed specified rated torque which leads to premature gear failure. L293D motor driver module protects controller from EMI (Electromagnetic Interference) signals which are caused by sudden directional change of motors. Protractor of diameter $11.5 \mathrm{~cm}$ is used to measure the degree change during revolution. Protractor is fixed to the stand and center point of protractor which is exactly pointing to the shaft of the geared DC motor. Large diameter of protractor is taken so that observation of change in degree which is less than $1^{\circ}$ can be easily measured. Position degree indicator is placed on shaft which helps to measure the change in degree of final position to initial position during its one revolution. To minimize the parallax errors during each measurement of total degree change, a background line indicator is drawn exactly behind position degree indicator.

Consuming voltage across geared DC motor during its rotation is measured using voltmeter $\left(\mathrm{V}_{\mathrm{C}}\right)$ as shown in Fig. 9.

\section{Results and discussions}

$\mathrm{RE}_{\mathrm{S}}$ values are analyzed for 10 \& 30RPM GDCSM with L293D motor driver module which is operated with supply voltage of $10+0.1 \% \mathrm{~V}$. They are operated at $1 \mathrm{RPM}$ and analyzed at value of $\boldsymbol{A}$ during horizontal or vertical movement. Initial $120,000 \mu$ s of $\boldsymbol{D}$ is assumed to calibrate the actual total steps per revolution at constant value of $\boldsymbol{A}$. During calibration process of actual Steps per Revolution, consuming voltage variations of GDCSM are represented as initial consuming voltage change $\left(\mathbf{V}_{\mathrm{cal}}\right)$. Initial calibration of actual steps per revolution during vertical movement of GDCSM is considered as same as the initial calibrated values of actual Steps per Revolution during horizontal movement of GDCSM. Step angle delay time

Fig. 8 10RPM GDCSM vertical rotation

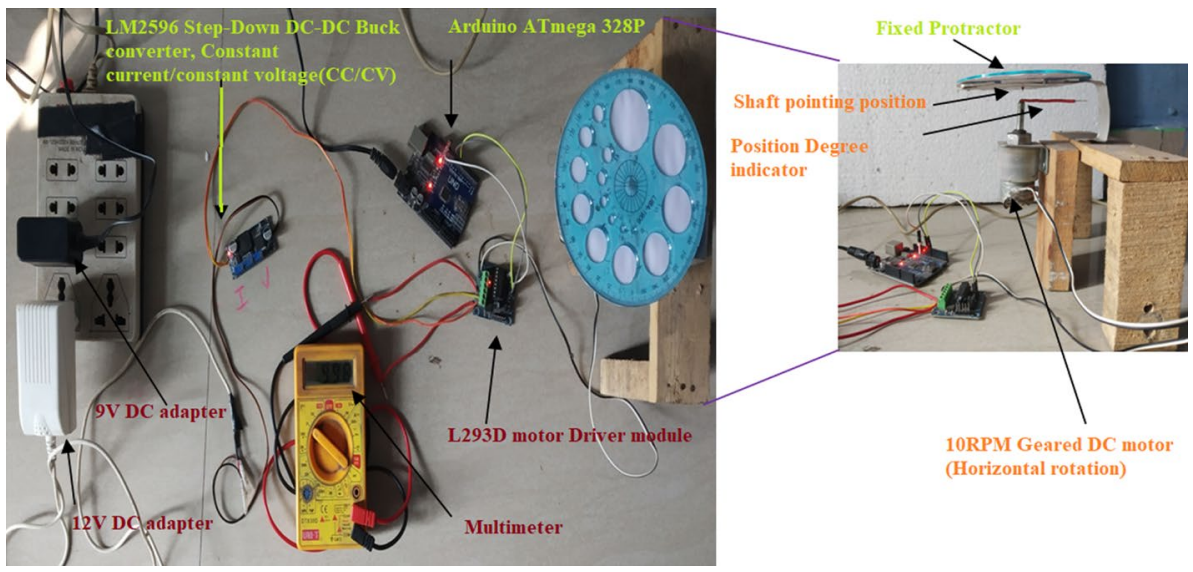


Fig. 9 Schematic diagram

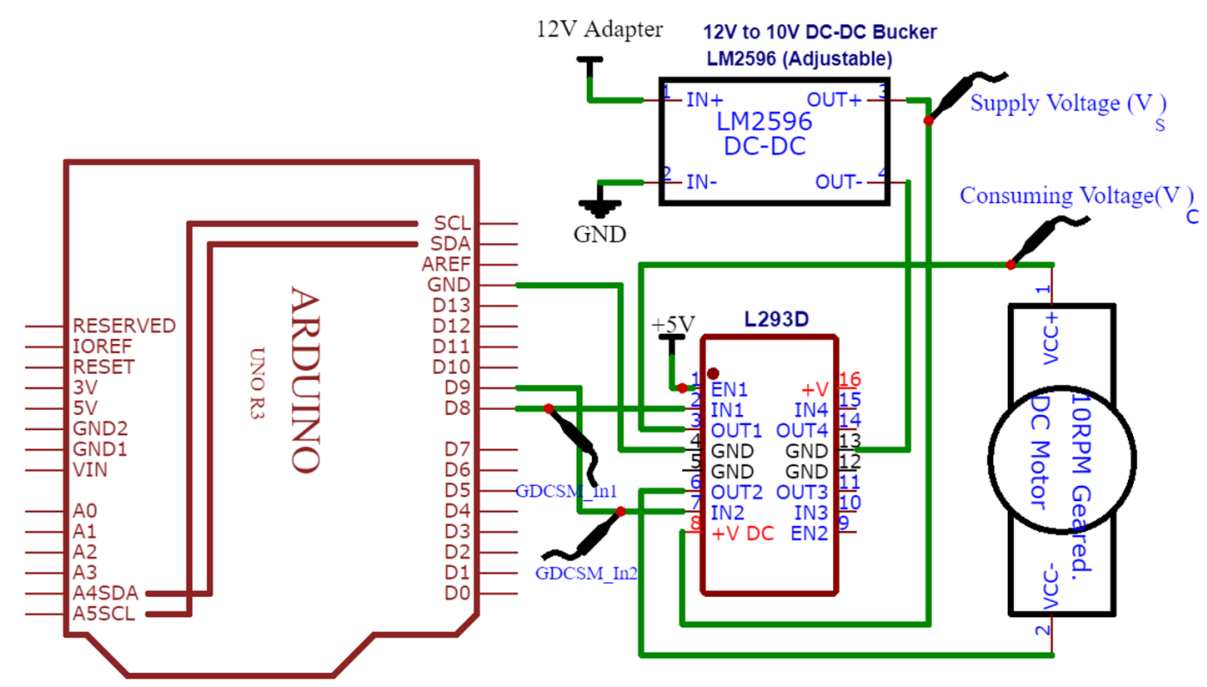

(A) of GDCSM is chosen based on its corresponding value of $\mathbf{R E}_{\mathrm{S}}$ which is less than or equal to $\mathbf{R E}_{\mathrm{s}}$ value of stepper motor models like I or III or V. Value of $A$ is chosen such that its corresponding value of Degrees per step lies within the range of $1^{\circ}$ to $7^{\circ}$. During horizontal or vertical movement at $0.0 \mathrm{~ms}$ of $\boldsymbol{A}$ there is no change in rotation of GDCSM which looks like no change in rotation of stepper motor at $0^{\circ}$ angular position.

Acceptable slippage degree tolerance is validation parameter used to compare $\mathbf{R E}_{\mathrm{S}}$ values of GDCSM with respect to speed variations. Generally value of acceptable slippage degree tolerance is considered at $1 \%$ of tolerance. So that its value of Measured degree per one revolution $\left(\boldsymbol{M}_{\mathrm{D}}\right)$ lies within the range of $-356.4^{\circ}$ to $363.6^{\circ}$ and its corresponding value of acceptable slippage degree per revolution is $\pm 3.6^{\circ}$.

During horizontal movement of stepper motor model I has $0.7 \%$ of $\mathbf{R E}_{s}$, and model III or V has $0.3 \%$ of $\mathbf{R E}$. $_{\text {. }}$.

During vertical movement of stepper motor model I has $0.6 \%$ of $\mathbf{R E} \mathbf{s}_{\mathrm{s}}$, model III has $0.3 \%$ of $\mathbf{R E} \mathbf{s}_{\mathrm{s}}$ and model $\mathrm{V}$ has $0.1 \%$ of $\mathbf{R E} s$.

\subsection{Switching time signals}

Digital signals of Microcontroller are used to control the degree change of Stepper and GDCSM motors. Digital control signals are given to motor driver from microcontroller. So Timing diagram of Digital signals for required degree change is analyzed using Proteus 8 professional software [24]. Designed instructions of GDCSM using Arduino IDE in terms of Hex file are uploaded into Arduino emulator in Proteus simulator.

Holding a solar panel (weight of $300 \mathrm{~g}$ ) at a particular angle during vertical (elevated) movement using stepper motor model I is not possible because it has low torque. Model II stepper motor is unable to hold the tracked elevated angle of solar panel even it has high holding torque. So 10RPM geared DC motor is used to hold the elevated tracking of solar panel as shown in Fig. 10. The sun tracking is based on degree of change in elevated axis. So geared DC motor is converted into stepper motor behavior using microcontroller switching delay time signal.

Experimentally calibrated Actual Steps per revolution of 10RPM GDCSM and 30RPM GDCSM during vertically rotation is taken for simulation using initial calibration method as shown in Tables 3 and 7.

Digital signal simulation is analyzed at the controlling speed of 1RPM for required degree change during vertical rotation. Based on measured Degrees per step, simulation analysis is carried on following motors such as 10 RPM GDCSM has 1.88 Degree per step at value of $\boldsymbol{A}$ (Step angle delay time) is $20 \mathrm{~ms}$. 30 RPM GDCSM has 1.6 Degree per step at value of $\boldsymbol{A}$ is $5 \mathrm{~ms}$. Model I (28byj-48 Unipolar stepper motor) has 0.18 Degree per step and model II (STP43d1027 Bipolar stepper motor) has 1.8 Degree per step.

Digital signals for required degree $\left(1^{\circ}, 2^{0}, 5^{\circ}, \& 10^{\circ}\right)$ change of 10RPM GDCSM, 30RPM GDCSM are analyzed with stepper motor model I (Unipolar stepper) \& model II (Bipolar stepper) as shown in Figs. 11 and 12.

Digital signal of 10PRM \& 30RPM GDCSM at required degree of $1^{\circ}$ is similar to model II (STP-43d1027). There is no pulse generation (no step movement) compared with model I (28byj-48) as shown in Fig. 11.(A.ii, iii, iv). Actual degree per change in step movement of model II, 10RPM \& 30RPM GDCSM are greater than the required degree change of $1^{\circ}$ which results no pulse generation.

At time interval of $0.4 \mathrm{~s}$ for required degree change of $2^{\circ}$, model II \& model I have digital value of $1001,10 R P M \&$ 30RPM GDCSM has two pulses. Observed that each pulse has fixed width and Fixed time interval between the pulses. 10RPM GDCSM has $20 \mathrm{~ms}$ of fixed width of each pulse. 30RPM GDCSM has $5 \mathrm{~ms}$ of fixed width of each pulse 
Fig. 10 10RPM GDCSM used to track the sun elevated axis in Dual axis solar tracking application
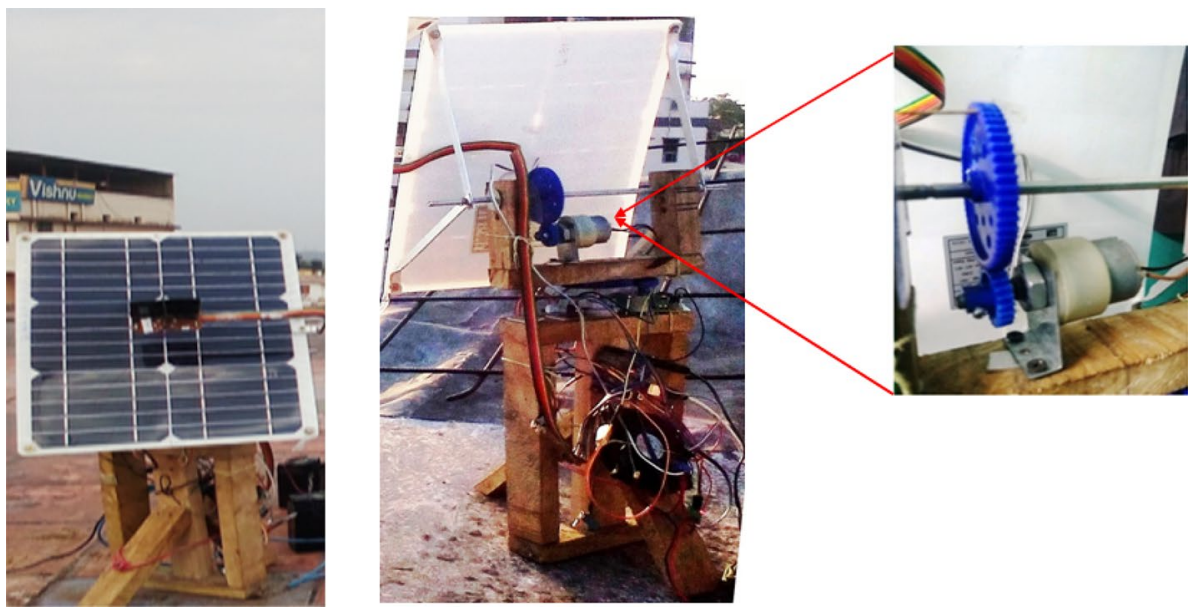

(A.i) 28byj-48, ULN2003A, 5V, 1 Degree

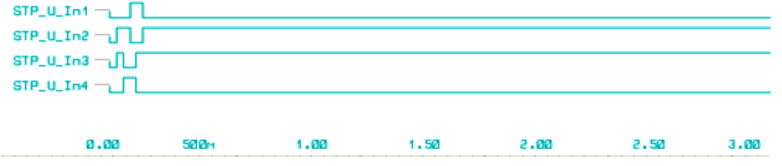

(A.ii) STP-43d1027, L293D, 10V, 1 Degree

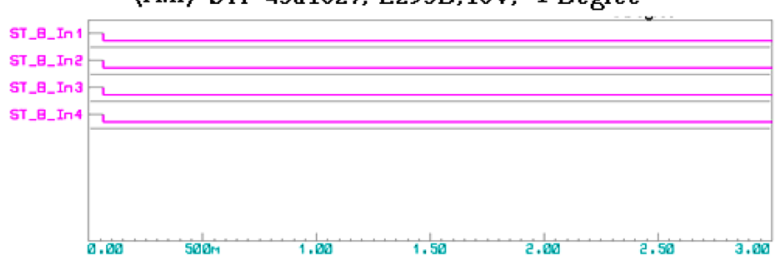

(A.iii) 10RPM GDCSM, 10V, A 5ms, 1 Degree

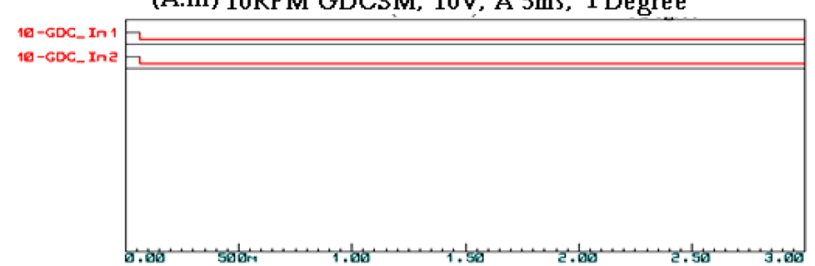

(A.iv) 30 RPM GDCSM, 10V, A 5ms, 1 Degree

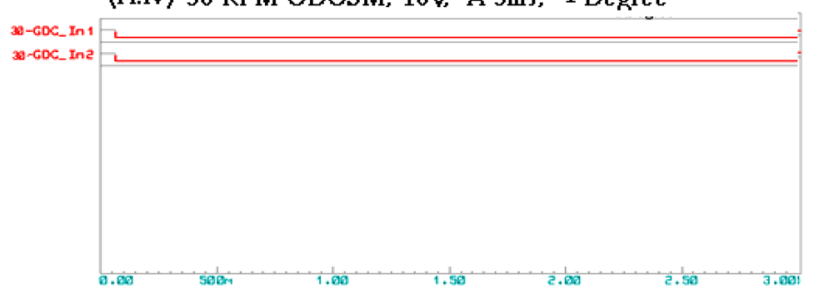

(B.i) 28byj-48, ULN2003A, 5V, 2 Degree

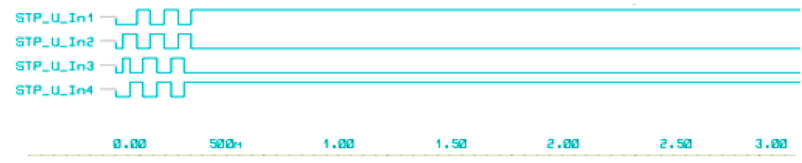

(B.ii) STP-43d1027, L293D,10V, 2 Degree

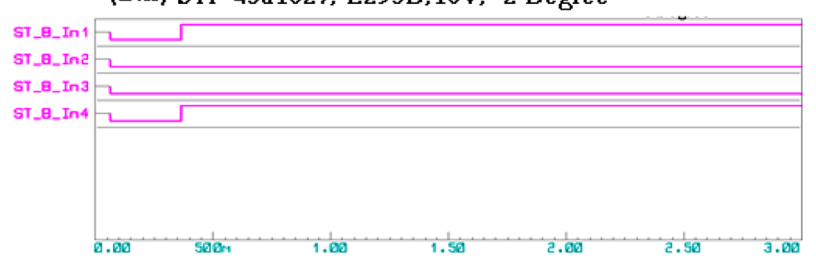

(B.iii) 10RPM GDCSM, 10V, A 5ms, 2 Degree

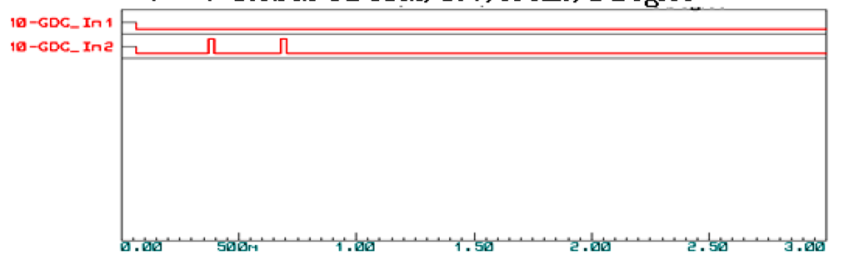

(B.iv) 30 RPM GDCSM, 10V A 5ms, 2 Degree

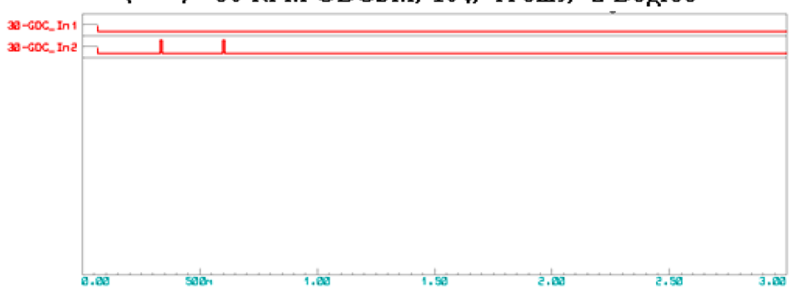

Fig. 11 Digital signals with respect to time for required degree change of $(A) 1^{\circ},(B) 2^{\circ}$

as shown in Fig. 11 (B.iii \& iv). Fixed width of the pulse represent fixed degree per step. Width of the pulse depends on the Step angle delay time (A) which is calibrated using initial method of calibration. Fixed time interval between pulses depends on RPM condition. RPM depends on Step delay time.
At time interval of $0.7 \mathrm{~s}$ for required degree change of $5^{\circ}$, model II has digital value of 0101 , model I has digital value of 1010, 10RPM GDCSM has three pulses with Fixed pulse width of $20 \mathrm{~ms}$ and Fixed time interval between the pulses. 30RPM GDCSM has four pulses with Fixed pulse width of $5 \mathrm{~ms}$ and Fixed time interval between the pulses as shown in Fig. 12.(C). 
(C.i) 28byj-48,ULN2003A, 5V, 5 Degree

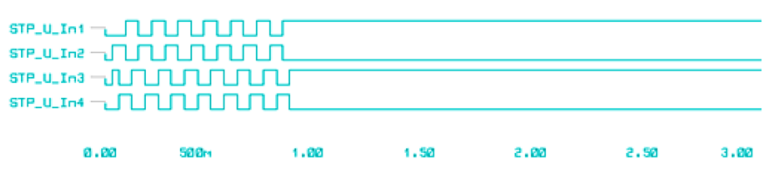

(C.ii) STP-43d1027, 1293D, 10V, 5 Degree

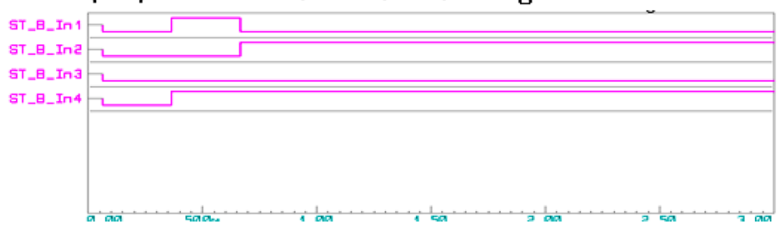

(C.iii) 10RPM GDCSM,L293D, 10V, 5 Degree

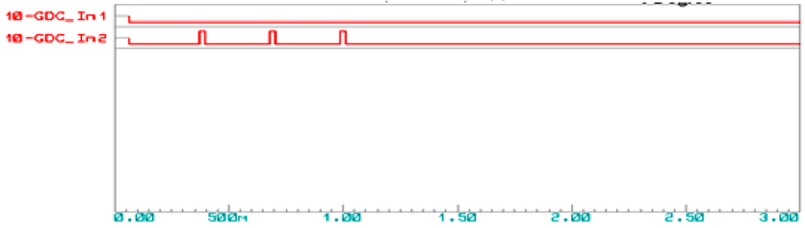

(C.iv) 30RPM GDCSM, L293D, 10V, 5 Degree

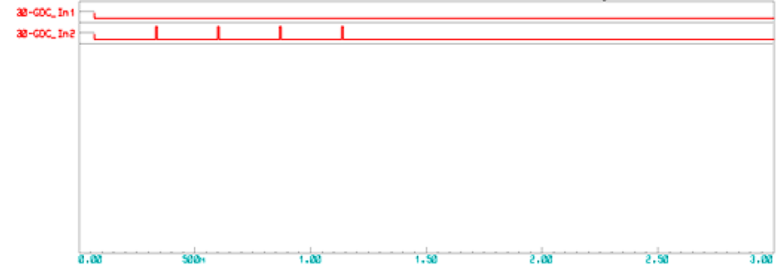

(D.i) 28byj-48,ULN2003A, 5V,10 Degree

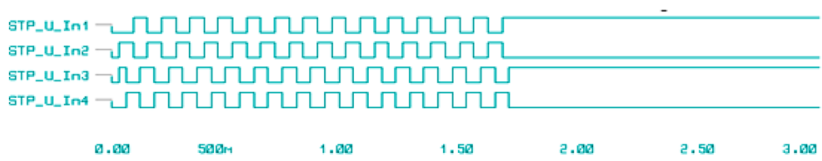

(D.ii) STP-43d1027, 1293D, 10V, 10 Degree

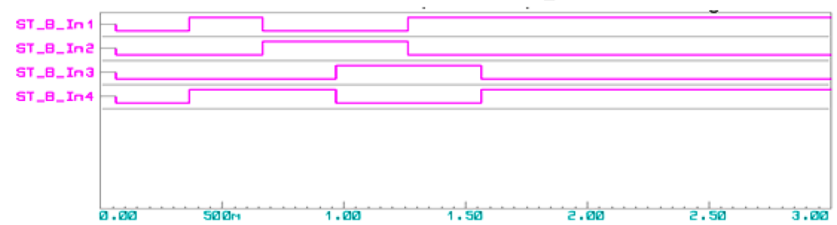

(D.iii) 10RPM GDCSM,L293D, 10V,10 Degree

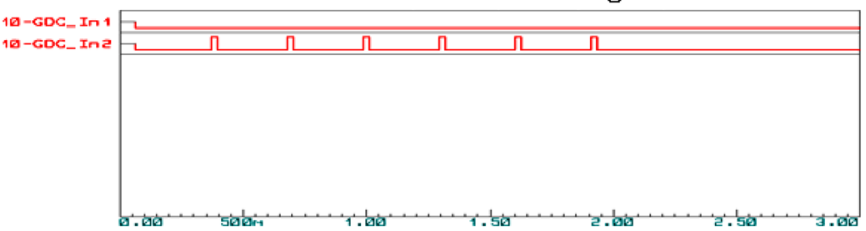

(D.iv) 30RPM GDCSM, L293D, 10V,10 Degree

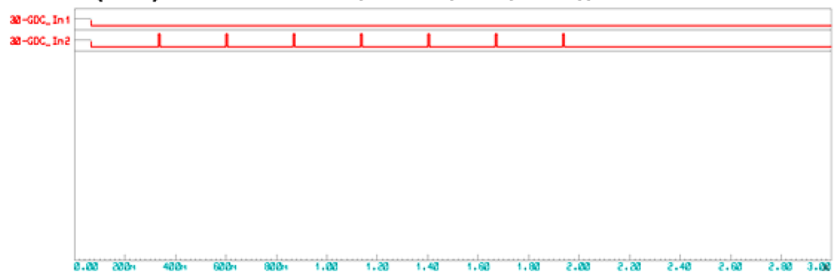

Fig. 12 Digital signals with respect to time for required degree change of (C) $5^{\circ},(D) 10^{\circ}$

At time interval of $2 \mathrm{~s}$ for required degree change of $10^{\circ}$, 10RPM GDCSM has six pulses with Fixed pulse width of $20 \mathrm{~ms}$ and Fixed time interval between the pulses. 30RPM GDCSM has seven pulses with Fixed pulse width of $5 \mathrm{~ms}$ and Fixed time interval between the pulses as shown in Fig. 12.(D). $285 \mathrm{~ms}$ of fixed time interval between pulses is existed for 10RPM GDCSM when it is operated at 1 RPM. $260 \mathrm{~ms}$ of fixed time interval between pulses is existed for 30RPM GDCSM. Observed that there is no change of fixed time interval between pulses for various required degree change of $2^{\circ}, 5^{\circ}$ and $10^{\circ}$ as shown in Fig. 11.(B.iii, iv), Fig. 12. (C.iii, iv) and Fig. 12.(D.iii, iv).

Observed that increase in required degree of change increases the number of pulses which is similar to stepper motor digital control signals as shown in Fig. 12. As the controlling speed is increased, then fixed time interval between the pulses is decreased.

\subsection{RPM GDCSM}

\subsubsection{Horizontal movement}

10RPM GDCSM has $0.0 \%$ of $\mathbf{R E}_{\mathrm{s}}$ at $20 \mathrm{~ms}$ of $\boldsymbol{A}$ with fixed angular change in position of $1.85^{\circ}$ Degrees per step and its corresponding value of $\Delta$ is $-0.29 \%$. It has $0.0 \%$ of $\mathbf{R E}$ $\mathrm{s}$ at $40 \mathrm{~ms}$ of $\boldsymbol{A}$ with fixed change in angular position of $3^{\circ}$ Degrees per step and its corresponding value of $\Delta$ is $-0.39 \%$.

It has $0.6 \%$ of $\mathbf{R E}_{\mathrm{s}}$ at $25 \mathrm{~ms}$ of $\boldsymbol{A}$ with constant change in angular position of $2.08^{\circ}$ Degrees per step and its corresponding value of $\Delta$ is $-0.29 \%$ as shown in Table 2 .

\subsubsection{Vertical movement}

10RPM GDCSM has $0.0 \%$ of RE ${ }_{S}$ at $20 \mathrm{~ms}$ of $\boldsymbol{A}$ with fixed change in angular position of $1.85^{\circ}$ Degrees per step and its corresponding value of $\Delta$ is $-0.29 \%$. At $40 \mathrm{~ms}$ of $\boldsymbol{A}$, it has $0.0 \%$ of $\mathbf{R E}_{\mathrm{S}}$ with change in angular position of $3^{\circ}$ Degrees per step and its corresponding value of $\Delta$ is $-0.39 \%$ as shown in Table 3. 
Table 2 RE $_{\mathrm{S}}$ vs $A$ of $10 \mathrm{RPM}$ GDCSM horizontal movement

\begin{tabular}{|c|c|c|c|c|c|c|c|c|}
\hline $\mathrm{V}_{c a l}(\mathrm{~V})$ & $A(\mathrm{~ms})$ & Steps/rev & Degree/step & $\mathrm{M}_{D}$ & Slip degree/Rev. & $\mathbf{R E}_{\mathrm{s}}(\%)$ & $\mathrm{V}_{C}(\mathrm{~V})$ & $\Delta(\%)$ \\
\hline 10_10.01 & 0 & & & & & & & \\
\hline 9.99_10.01 & 10 & 340 & $1.06^{\circ}$ & $413.5^{\circ}$ & $53.5^{\circ}$ & 14.9 & 9.98_10 & -0.2 \\
\hline 9.99_10.01 & 12 & 283 & $1.27^{\circ}$ & $390^{\circ}$ & $30^{\circ}$ & 8.3 & 9.98_10 & -0.2 \\
\hline 9.99_10.01 & 14 & 250 & $1.44^{\circ}$ & $374^{\circ}$ & $14^{\circ}$ & 3.9 & 9.98_10 & -0.2 \\
\hline 9.98_10.01 & 15 & 236 & $1.53^{\circ}$ & $375^{\circ}$ & $15^{\circ}$ & 4.2 & 9.98_10 & -0.2 \\
\hline 9.98_10.01 & 20 & 195 & $1.85^{\circ}$ & $360^{\circ}$ & $0^{\circ}$ & 0.0 & 9.98_10.01 & -0.29 \\
\hline 9.98_10.01 & 25 & 173 & $2.08^{\circ}$ & $362^{\circ}$ & $2^{\circ}$ & 0.6 & 9.98_10.01 & -0.29 \\
\hline 9.97_10.01 & 30 & 146 & $2.46^{\circ}$ & $357^{\circ}$ & $-3^{\circ}$ & 0.8 & 9.97_10.01 & -0.39 \\
\hline 9.96_10.01 & 40 & 120 & $3^{\circ}$ & $360^{\circ}$ & $0^{\circ}$ & 0.0 & 9.97_10.01 & -0.39 \\
\hline
\end{tabular}

Table $3 \mathbf{R E}_{\mathrm{s}}$ vs $A$ of $10 \mathrm{RPM}$ GDCSM vertical movement

\begin{tabular}{|c|c|c|c|c|c|c|c|c|}
\hline $\mathrm{V}_{c a l}(\mathrm{~V})$ & $A(\mathrm{~ms})$ & Steps/Rev & Degree/step & $M_{D}$ & Slip degree/Rev. & $\mathbf{R E}_{\mathrm{s}}(\%)$ & $\mathrm{V}_{C}(\mathrm{~V})$ & $\Delta(\%)$ \\
\hline 10_10.01 & 0 & & & & & & & \\
\hline 9.99_10.01 & 10 & 340 & $1.06^{\circ}$ & $417^{\circ}$ & $57^{\circ}$ & 15.8 & 9.98_10 & -0.2 \\
\hline 9.99_10.01 & 12 & 283 & $1.27^{\circ}$ & $390.5^{\circ}$ & $30.5^{\circ}$ & 8.5 & 9.98_10 & -0.2 \\
\hline 9.99_10.01 & 14 & 250 & $1.44^{\circ}$ & $387^{\circ}$ & $27^{\circ}$ & 7.5 & $9.98 \_10$ & -0.2 \\
\hline 9.98_10.01 & 15 & 236 & $1.53^{\circ}$ & $381^{\circ}$ & $21^{\circ}$ & 5.8 & 9.98_10 & -0.2 \\
\hline 9.98_10.01 & 20 & 195 & $1.85^{\circ}$ & $360^{\circ}$ & $0^{\circ}$ & 0.0 & 9.98_10.01 & -0.29 \\
\hline 9.98_10.01 & 25 & 173 & $2.08^{\circ}$ & $368.5^{\circ}$ & $8.5^{\circ}$ & 2.4 & 9.97_10.01 & -0.39 \\
\hline 9.97_10.01 & 30 & 146.20 & $2.46^{\circ}$ & $356.5^{\circ}$ & $-3.5^{\circ}$ & 1.0 & 9.97_10.01 & -0.39 \\
\hline 9.96_10.01 & 40 & 120 & $3^{\circ}$ & $360^{\circ}$ & $0^{\circ}$ & 0.0 & $9.97 \_10.01$ & -0.39 \\
\hline
\end{tabular}

During horizontal movement, $\mathbf{R E}_{\mathrm{S}}$ value of 10RPM GDCSM is less than the stepper motors models I, III \& V at 20 or $40 \mathrm{~ms}$ of $\boldsymbol{A}$. At $25 \mathrm{~ms}$ of $\boldsymbol{A}, \mathbf{R E}{ }_{\mathrm{s}}$ value of $\mathbf{1 0 R P M}$ GDCSM is less than the stepper motor model I as shown in Fig. 13.

During vertical movement, $\mathbf{R E}_{\mathrm{S}}$ value of 10RPM GDCSM is less than the stepper motors models I, III \& $V$ at 20 or $40 \mathrm{~ms}$ of $\boldsymbol{A}$.

\subsubsection{RPM GDCSM speed variations}

Values of $\mathbf{R} \mathbf{E}_{S}$ with respect to speed variations are analyzed up to 3RPM during horizontal movement of 10RPM GDCSM as shown in Table 4.

At $40 \mathrm{~ms}$ of $\boldsymbol{A}$, during horizontal movement of 10RPM GDCSM has $1 \%$ of $\mathbf{R E}{ }_{\mathrm{S}}$ which is equal to acceptable slippage degree tolerance (i.e., $360 \pm 1 \%$ ) and greater than the

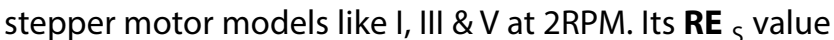
is larger than stepper motor models and acceptable slippage degree tolerance at $3 \mathrm{RPM}$.

At $20 \mathrm{~ms}$ of $\boldsymbol{A}$, its corresponding value of $\mathbf{R E}{ }_{\mathrm{S}}$ is $6.7 \%$ which is greater than the acceptable slippage degree tolerance at 2\&3RPM.

$\mathbf{R E}_{\mathrm{S}}$ values with respect to speed variations are analyzed up to 3RPM during vertical movement of 10RPM GDCSM as shown in Table 5.

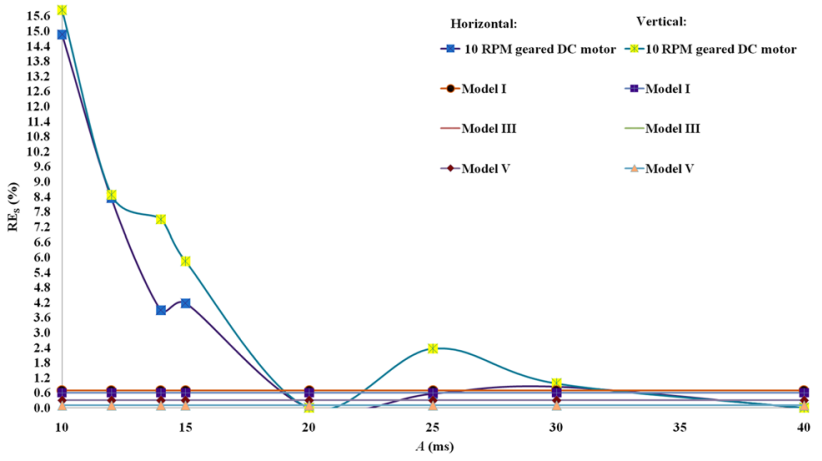

Fig. $13 \mathbf{R E}_{\mathrm{s}}$ vs Step angle delay time (A)

At 40 ms of $\boldsymbol{A}, 10 R P M$ GDCSM during vertical movement has $0.4 \%$ of $\mathbf{R E}{ }_{\mathrm{s}}$ which is less than acceptable slippage degree tolerance and stepper motor model I at 2RPM. Its $\mathbf{R E}_{\mathrm{S}}$ value is larger than stepper motor models and acceptable slippage degree tolerance at 3RPM.

At $20 \mathrm{~ms}$ of $\boldsymbol{A}$, it has $6.1 \%$ of $\mathbf{R E} \mathbf{s}_{\mathrm{S}}$ which is greater than the acceptable slippage degree tolerance at $2 \mathrm{RPM}$. RE $\mathrm{S}$ value is very large at $3 R P M$ also.

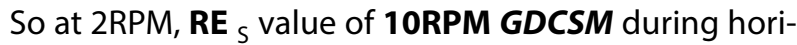
zontal or vertical movement at $40 \mathrm{~ms}$ of $\boldsymbol{A}$ is less than $20 \mathrm{~ms}$ of $\boldsymbol{A}$ as shown in Fig. 14.

10RPM GDCSM works like stepper motor at 20 or $40 \mathrm{~ms}$ of $\boldsymbol{A}$. Because RE ${ }_{\mathrm{s}}$ values of 10RPM GDCSM are less than 
the stepper motor models I, III \& V which are operated in both horizontal or vertical movement.

10RPM GDCSM at $40 \mathrm{~ms}$ of $\boldsymbol{A}$ is performed better than the 20 ms of $\boldsymbol{A}$ at 2RPM. At 2RPM during vertical movement of 10RPM GDCSM performs better than its horizontal movement, because its $\mathbf{R E} \mathrm{s}_{\mathrm{S}}$ value during vertical movement is less than the horizontal movement as well as vertical movement of stepper motor model I. As the speed is increased from 3RPM, its slip degree per revolution is increased and their corresponding value of $\mathbf{R E}_{\mathbf{S}}$ is increased. At higher RPMs implementation of 10RPM GDCSM is possible when value of $\mathbf{R E}_{\mathrm{S}}$ is less than or equal to $1 \%$. So minimization of slip degree per revolution is required as speed increases which is less than or equal to acceptable slippage degree tolerance.

\subsection{RPM GDCSM}

\subsubsection{Horizontal movement}

30RPM GDCSM has $0.1 \%$ of $\mathbf{R E}_{\mathrm{S}}$ at $20 \mathrm{~ms}$ of $\boldsymbol{A}$ with fixed change in angular position of $5.63^{\circ}$ Degrees per step. At $25 \mathrm{~ms}$ of $\boldsymbol{A}$, it has $0.1 \%$ of $\mathbf{R E}_{\mathrm{s}}$ with constant angular position of $6.55^{\circ}$ Degrees per step. It has $-0.29 \%$ of $\Delta$ at 20 or $25 \mathrm{~ms}$ of $\boldsymbol{A}$.

At $15 \mathrm{~ms}$ of $\boldsymbol{A}$, it has $0.7 \%$ of $\mathbf{R E}_{\mathrm{S}}$ with $4.54^{\circ}$ Degrees per step and its corresponding value of $\Delta$ is $-0.19 \%$. At $6 \mathrm{~ms}$ of $\boldsymbol{A}$, it has $0.4 \%$ of $\mathbf{R E}_{\mathrm{S}}$ with fixed angular change in position of $1.6^{\circ}$ Degrees per step and its corresponding value of $\Delta$ is $-0.19 \%$ as shown in Table 6 .

\subsubsection{Vertical movement}

Step angle delay time $(\boldsymbol{A})$ values are considered up to $25 \mathrm{~ms}$ for 30RPM GDCSM, and their corresponding RE s values are greater than the stepper motor models I, III \& V as shown in Table 7.

During horizontal movement, 30RPM GDCSM has $\mathbf{R E}_{\mathrm{s}}$ values less than the stepper motor model I at 6 or $15 \mathrm{~ms}$ of $A$ as shown in Fig. 15. At 20 or $25 \mathrm{~ms}$ of $\boldsymbol{A}$ and their corresponding $\mathbf{R E}_{\mathrm{S}}$ values are less than the stepper motors models I, III \& V.

Table 4 Speed vs RE ${ }_{5}(\%)$ of $10 \mathrm{RPM}$ GDCSM during horizontal movement

\begin{tabular}{|c|c|c|c|c|c|}
\hline \multirow[t]{3}{*}{ RPM } & \multicolumn{5}{|l|}{$\operatorname{RE}_{S}(\%)$} \\
\hline & \multicolumn{2}{|c|}{ Step angle delay time(ms) } & \multicolumn{3}{|c|}{ Stepper Model } \\
\hline & $A$ is 20 & $A$ is 40 & I & III & V \\
\hline 1 & 0.0 & 0.0 & 0.7 & 0.3 & 0.3 \\
\hline 2 & 6.7 & 1.0 & 0.4 & 0.3 & 0.1 \\
\hline 3 & 20.8 & 10.8 & 0.3 & 0.1 & 0.1 \\
\hline
\end{tabular}

Table 5 Speed versus $\mathbf{R E}{ }_{s}(\%)$ of $10 \mathrm{RPM}$ GDCSM during vertical movement

\begin{tabular}{|c|c|c|c|c|c|}
\hline \multirow[t]{3}{*}{ RPM } & \multicolumn{5}{|c|}{$\mathbf{R E}_{\mathrm{s}}(\%)$} \\
\hline & \multicolumn{2}{|c|}{ Step angle delay time(ms) } & \multicolumn{3}{|c|}{ Stepper Model } \\
\hline & $A$ is 20 & $A$ is 40 & I & III & V \\
\hline 1 & 0.0 & 0.0 & 0.6 & 0.3 & 0.1 \\
\hline 2 & 6.1 & 0.4 & 0.6 & 0.3 & 0.1 \\
\hline 3 & 19.4 & 10.3 & 0.6 & 0.1 & 0.1 \\
\hline
\end{tabular}

During vertical movement, 30RPM GDCSM does not behave like stepper motor at values of $\boldsymbol{A}$ which are considered up to $25 \mathrm{~ms}$, because their corresponding values of $\mathbf{R E}_{\mathrm{s}}$ are greater than the stepper motors models I, III \& $V$. There is large value of slip degree per revolution which is due to frictional losses during vertical movement. At $1 \mathrm{RPM}, \mathbf{R E}_{\mathrm{S}}$ value at $25 \mathrm{~ms}$ of $\boldsymbol{A}$ is less than the $\mathbf{R E}_{\mathrm{S}}$ value at 6 or 15 or $20 \mathrm{~ms}$ of $\boldsymbol{A}$. At $25 \mathrm{~ms}$ of $\boldsymbol{A}$, it behaves like stepper motor during vertical movement If slip degree per revolution is controlled below $1 \%$ of $\mathbf{R E}_{\mathrm{s}}$.

During both horizontal and vertical movement of 30RPM GDCSM at 1RPM, its RE ${ }_{\mathrm{s}}$ value at $25 \mathrm{~ms}$ of $\boldsymbol{A}$ is less than $\mathbf{R E}_{\mathrm{s}}$ value of $\boldsymbol{A}$ at 6 or 15 or $20 \mathrm{~ms}$.

\subsubsection{RPM GDCSM speed variations}

$\mathbf{R E}_{\mathrm{S}}$ values with respect to speed variations are analyzed up to 5RPM during horizontal movement of 30RPM GDCSM as shown in Table 8.

At 25 ms of $\boldsymbol{A}$, during horizontal movement of 30RPM GDCSM has $0.3 \%$ of $\mathbf{R E}{ }_{\mathrm{s}}$ which is less than stepper motor model $\mathrm{V}$ and acceptable slippage degree tolerance but equals to stepper motor model III at 2RPM. At 3RPM, it has $0.8 \%$ of $\mathbf{R E} \mathbf{s}_{\mathrm{s}}$ which is greater than stepper motor models but less than the acceptable slippage degree tolerance.

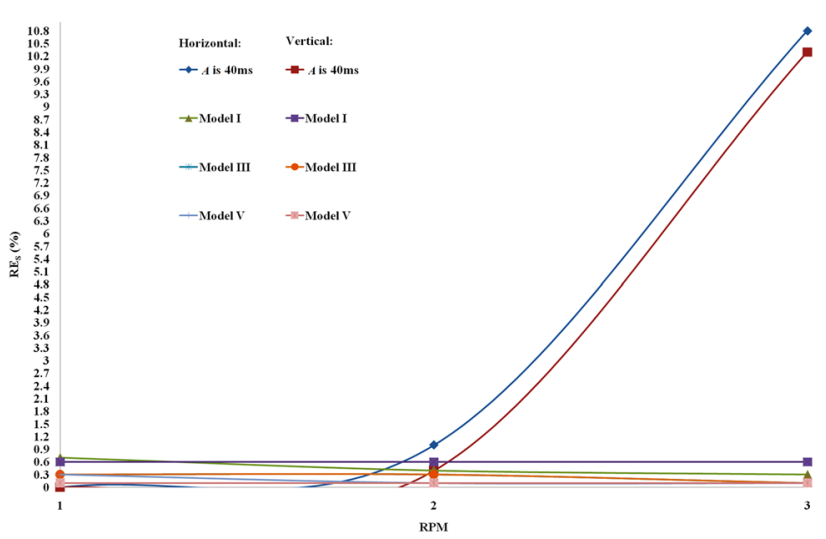

Fig. 14 Speed versus $\mathbf{R E}_{\mathrm{s}}(\%)$ of $10 \mathrm{RPM}$ GDCSM at $40 \mathrm{~ms}$ of step angle delay time $(A)$ 
Table $6 \mathbf{R E}_{\mathrm{S}}$ versus $A$ of $30 \mathrm{RPM}$ GDCSM horizontal movement

\begin{tabular}{|c|c|c|c|c|c|c|c|c|}
\hline $\mathrm{V}_{\text {cal }}(\mathrm{V})$ & $A(\mathrm{~ms})$ & Steps/Rev & Degree/step & $M_{D}$ & Slip degree/Rev. & $\mathbf{R E}_{\mathrm{s}}(\%)$ & $\mathrm{V}_{C}(\mathrm{~V})$ & $\Delta(\%)$ \\
\hline 10_10.01 & 0 & & & & & & & \\
\hline 9.99_10.01 & 5 & 292.19 & $1.23^{\circ}$ & $337^{\circ}$ & $-23^{\circ}$ & 6.4 & $9.99 \_10.01$ & -0.19 \\
\hline 9.99_10.01 & 6 & 224.69 & $1.6^{\circ}$ & $361.5^{\circ}$ & $1.5^{\circ}$ & 0.4 & 9.99_10.01 & -0.19 \\
\hline 9.99_10.01 & 7 & 177.00 & $2.03^{\circ}$ & $351.5^{\circ}$ & $-8.5^{\circ}$ & 2.4 & 9.99_10.01 & -0.19 \\
\hline 9.99_10.01 & 8 & 142.59 & $2.52^{\circ}$ & $353.5^{\circ}$ & $-6.5^{\circ}$ & 1.8 & 9.99_10.01 & -0.19 \\
\hline 9.99_10.01 & 9 & 126.35 & $2.85^{\circ}$ & $357^{\circ}$ & $-3^{\circ}$ & 0.8 & 9.99_10.01 & -0.19 \\
\hline 9.99_10.01 & 10 & 111.31 & $3.23^{\circ}$ & $357^{\circ}$ & $-3^{\circ}$ & 0.8 & 9.99_10.01 & -0.19 \\
\hline 9.99_10.01 & 15 & 79.33 & $4.54^{\circ}$ & $362.5^{\circ}$ & $2.5^{\circ}$ & 0.7 & 9.99_10.01 & -0.19 \\
\hline 9.99_10.01 & 20 & 64 & $5.63^{\circ}$ & $359.5^{\circ}$ & $-0.5^{\circ}$ & 0.1 & 9.98_10.01 & -0.29 \\
\hline 9.98_10.01 & 25 & 55 & $6.55^{\circ}$ & $359.5^{\circ}$ & $-0.5^{\circ}$ & 0.1 & 9.98_10.01 & -0.29 \\
\hline
\end{tabular}

Table 7 RE s versus $A$ of 30RPM GDCSM vertical movement

\begin{tabular}{|c|c|c|c|c|c|c|c|c|}
\hline $\mathrm{V}_{\text {cal }}(\mathrm{V})$ & $A(\mathrm{~ms})$ & Steps/Rev & Degree/step & $\mathrm{M}_{D}$ & Slip degree/Rev. & $\mathbf{R E}_{\mathrm{s}}(\%)$ & $\mathrm{V}_{\mathrm{C}}(\mathrm{V})$ & $\Delta(\%)$ \\
\hline 10_10.01 & 0 & 0 & & & & & & \\
\hline 9.99_10.01 & 5 & 292.19 & $1.23^{\circ}$ & $346^{\circ}$ & $-14^{\circ}$ & 3.9 & 9.99_10.01 & -0.19 \\
\hline 9.99_10.01 & 6 & 224.69 & $1.6^{\circ}$ & $377^{\circ}$ & $17^{\circ}$ & 4.7 & 9.99_10.01 & -0.19 \\
\hline 9.99_10.01 & 7 & 177 & $2.03^{\circ}$ & $386.5^{\circ}$ & $26.5^{\circ}$ & 7.4 & 9.99_10.01 & -0.19 \\
\hline 9.99_10.01 & 8 & 142.59 & $2.52^{\circ}$ & $370^{\circ}$ & $10^{\circ}$ & 2.8 & 9.99_10.01 & -0.19 \\
\hline 9.99_10.01 & 9 & 126.35 & $2.85^{\circ}$ & $381.5^{\circ}$ & $21.5^{\circ}$ & 6.0 & 9.99_10.01 & -0.19 \\
\hline 9.99_10.01 & 10 & 111.31 & $3.23^{\circ}$ & $375^{\circ}$ & $15^{\circ}$ & 4.2 & 9.99_10.01 & -0.19 \\
\hline 9.99_10.01 & 15 & 79.33 & $4.54^{\circ}$ & $378.5^{\circ}$ & $18.5^{\circ}$ & 5.1 & 9.98_10.01 & -0.29 \\
\hline 9.99_10.01 & 20 & 64 & $5.63^{\circ}$ & $373^{\circ}$ & $13^{\circ}$ & 3.6 & 9.98_10.01 & -0.29 \\
\hline 9.98_10.01 & 25 & 55 & $6.55^{\circ}$ & $367^{\circ}$ & $7^{\circ}$ & 1.9 & 9.97_10.01 & -0.39 \\
\hline
\end{tabular}

stepper models. At $5 \mathrm{RPM}$, it has $0 \%$ of $\mathbf{R E} \mathbf{s}_{\mathrm{s}}$ which is less than the slip degree per revolution and stepper models.

At $15 \mathrm{~ms}$ of $\boldsymbol{A}$, it has $0.7 \%$ of $\mathbf{R E}{ }_{\mathrm{s}}$ which is greater than stepper motor models but less than the acceptable slippage degree tolerance at 2RPM. At 3RPM, it has $7.5 \%$ of RE $\mathrm{s}$ which is greater than stepper motor models and acceptable slippage degree tolerance. At 4RPM, it has $4.7 \%$ of $\mathbf{R E}{ }_{S}$ which is greater than slip degree per revolution and stepper models. At 5RPM, it has $1.9 \%$ of $\mathbf{R E}_{\mathrm{S}}$ which is greater than the slip degree per revolution and stepper models.

At $6 \mathrm{~ms}$ of $\boldsymbol{A}$, as speed is increased from 2 to $5 \mathrm{RPM}$ it has very large values of $\mathbf{R E}{ }_{\mathrm{S}}$ which are greater than stepper motor models and acceptable slippage degree tolerance.

$\mathbf{R E}_{\mathbf{S}}$ with respect to speed variations are analyzed up to 5RPM during vertical movement of 30RPM GDCSM as shown in Table 9.

As speed is increased from 2 to $4 \mathrm{RPM}$, during vertical movement of 30RPM GDCSM at 15 or 20 or 25 of $\boldsymbol{A}$ and their corresponding values of $\mathbf{R E} \mathbf{S}_{\mathrm{S}}$ are very large while compared with stepper motor models and acceptable slippage degree tolerance. At $5 \mathrm{RPM}$, it has $0.4 \%$ of $\mathbf{R E}_{\mathrm{S}}$ which is less than stepper motor model I and acceptable slippage degree tolerance at values of $\boldsymbol{A}$ is 15 or $20 \mathrm{~ms}$. It has $1 \%$ of $\mathbf{R E}{ }_{\mathrm{S}}$ which is greater than stepper motor 
Table 8 Speed versus $\mathbf{R E}_{\mathrm{S}}$ (\%) of 30RPM GDCSM during horizontal movement

\begin{tabular}{|c|c|c|c|c|c|c|c|}
\hline \multirow[t]{3}{*}{ RPM } & \multicolumn{7}{|c|}{$\mathrm{RE}_{\mathrm{s}}(\%)$} \\
\hline & \multicolumn{4}{|c|}{ Step angle delay time (ms) } & \multicolumn{3}{|c|}{ Model } \\
\hline & $\boldsymbol{A}$ is 6 & $\boldsymbol{A}$ is 15 & $\boldsymbol{A}$ is 20 & $\boldsymbol{A}$ is 25 & I & III & V \\
\hline 1 & 0.4 & 0.7 & 0.1 & 0.1 & 0.7 & 0.3 & 0.3 \\
\hline 2 & 61.7 & 0.7 & 0 & 0.3 & 0.4 & 0.3 & 0.1 \\
\hline 3 & 43.9 & 7.5 & 0.6 & 0.8 & 0.3 & 0.1 & 0.1 \\
\hline 4 & 24.2 & 4.7 & 3.3 & 2.5 & 0.6 & 0.3 & 0.3 \\
\hline 5 & 10.3 & 1.9 & 1.4 & 0 & 0.4 & 0.0 & 0.0 \\
\hline
\end{tabular}

models and equal to acceptable slippage degree tolerance at $25 \mathrm{~ms}$ of $\boldsymbol{A}$. At $6 \mathrm{~ms}$ of $\boldsymbol{A}$, it has $10.6 \%$ of $\mathbf{R E}_{\mathrm{s}}$ which is greater than the stepper motor models and acceptable slippage degree tolerance at $5 \mathrm{RPM}$.

30RPM GDCSM at $25 \mathrm{~ms}$ of $\boldsymbol{A}$ is performed better than the 20 ms of $\boldsymbol{A}$ at 1RPM while considering both horizontal and vertical movements.

At 2RPM, during both horizontal and vertical movement it behaves like stepper motor when its vertical movement of $\mathbf{R E}_{\mathrm{S}}$ value is less than acceptable slippage degree tolerance as shown in Fig. 16.

As speed is increased from 3 to 4RPM its slip degree per revolution is increased and their corresponding value of $\mathbf{R E} \mathbf{S}_{\mathrm{S}}$ is increased. At higher RPMs implementation of 30RPM GDCSM is possible when value of $\mathbf{R E}_{\mathrm{s}}$ is less than or equal to $1 \%$. So minimization of slip degree per revolution is required as speed increases which should be less than or equal to acceptable slippage degree tolerance.

Analyzed that as step angle delay time $(\boldsymbol{A})$ is increased and its corresponding value of $\mathbf{R E}_{\mathbf{S}}$ is decreased during implementation of GDCSM. If RPM is increased motor speed is increased and its corresponding value of $\boldsymbol{D}$ decreases so that slippage error is increased. In stepping method slippage error increases means some steps are missed during motor rotation even when the step angle (i.e., Degree per step) is constant. This happens when delay time signal of $\boldsymbol{D} \mu \mathrm{s}$ which is passed between the steps is less than the actual execution time of delay instruction of microcontroller. Some steps are missed when RPM is increased which causes the increase in value of $\mathbf{R E} \mathbf{s}_{s}$.

\subsubsection{Motors cost and torque analysis}

Stepper motor 28byj-48 with Driver ULN2003A has low cost, low torque compared to other motors. It cannot hold vertical step movement (VSHP) in low-speed application of solar panel which has weight of $300 \mathrm{~g}$ [22]. Stepper motor (2 KG) STP-43d1027-01 with Driver L293N (H bridge) has high cost compared to other motors. It cannot hold vertical degree change of solar panel of weight $300 \mathrm{~g}$ during its vertical movement.10 \& 30RPM GDCSM has high torque as shown in Table 10. 10\& 30 RPM GDCSM motors can hold easily solar panel vertical step movement even there is disturbance of air flow over the panel.

\section{Conclusion}

Microcontroller-based geared DC motors under open loop condition with stepping method (GDCSM) is proposed in this work which behaves like stepper motor. Switching delay time signals are control parameters used in Stepping method. Initial calibration method helps to identify the steps per revolution of geared DC motors. Minimized tolerance of supply voltage $\left(\mathrm{V}_{\mathrm{S}}\right)$ of GDCSM using CC \& $\mathrm{CV}$ source helps to maintain the Fixed degree per step of GDCSM.
Table 9 Speed versus RE (\%) of 30RPM GDCSM during vertical movement

\begin{tabular}{|c|c|c|c|c|c|c|c|}
\hline \multirow[t]{3}{*}{ RPM } & \multicolumn{7}{|l|}{$\mathrm{RE}_{\mathrm{s}}(\%)$} \\
\hline & \multicolumn{4}{|c|}{ Step angle delay time (ms) } & \multicolumn{3}{|c|}{ Model } \\
\hline & $\boldsymbol{A}$ is 6 & $\boldsymbol{A}$ is 15 & $\boldsymbol{A}$ is 20 & $\boldsymbol{A}$ is 25 & I & III & $\mathrm{V}$ \\
\hline 1 & 4.7 & 5.1 & 3.6 & 1.9 & 0.6 & 0.3 & 0.1 \\
\hline 2 & 63.1 & 5 & 2.8 & 1.7 & 0.6 & 0.3 & 0.1 \\
\hline 3 & 43.3 & 9.6 & 5 & 2.1 & 0.6 & 0.1 & 0.1 \\
\hline 4 & 22.8 & 6.1 & 5.1 & 5.3 & 0.6 & 0.3 & 0.3 \\
\hline 5 & 10.6 & 0.4 & 0.4 & 1 & 0.6 & 0.1 & 0.1 \\
\hline
\end{tabular}




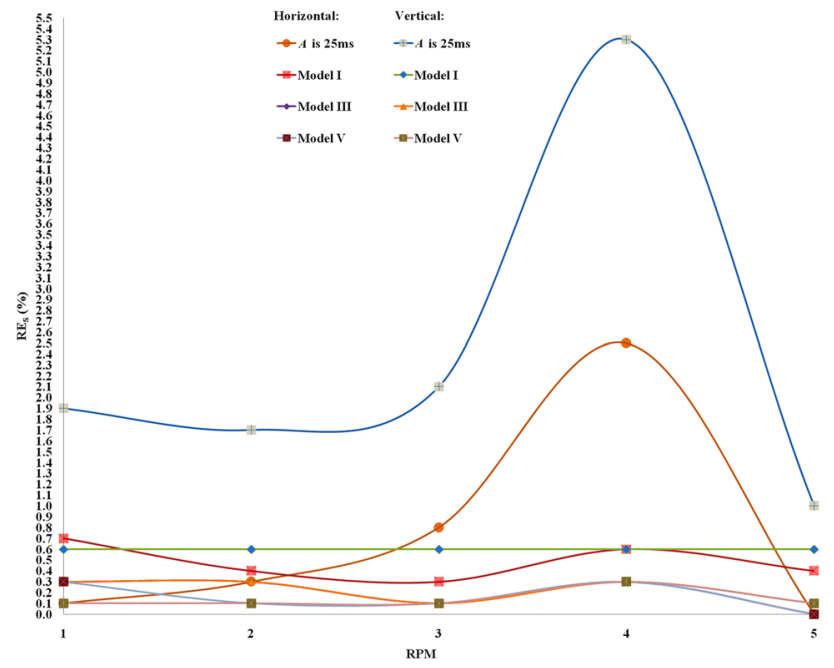

Fig. 16 Speed versus RE ${ }_{s}(\%)$ of 30RPM GDCSM at $25 \mathrm{~ms}$ of step angle delay time $(A)$

Table 10 Cost, Torque, Vertical step movement holding position (VSHP) of motors used in work

\begin{tabular}{|c|c|c|c|}
\hline & Cost (Rs.) & Torque (N-m) & VSHP \\
\hline \multicolumn{4}{|l|}{ Stepper motors } \\
\hline 28byj-48, ULN2003A. & 159 & 0.08 & No \\
\hline STP-43d1027-01, L293N. & 517 & 0.314 & No \\
\hline \multicolumn{4}{|l|}{ Geared DC motor (GDCSM) } \\
\hline 10RPM, L293D, LM2596 CC/CV. & 433 & 0.393 & Yes \\
\hline 30RPM, L293D, LM2596 CC/CV. & 418 & 0.423 & Yes \\
\hline
\end{tabular}

GDCSM motors are implemented in this work using micro-controller switching delay time signals. Using switching delay time signals, fixed degree per each step movement and required RPM are designed. Fixed degree per each step movement is designed based on fixed width of the pulse. Required RPM condition is implemented based on fixed time interval between the pulses.

Stepping method mechanism helps to operate degree based step movement of geared DC motors for low-speed tracking applications.

Simulation of Digital control signals of microcontroller for GDCSM and stepper motors model I \&ll are analyzed.

Relative slip degree error per revolution $\left(\mathbf{R E}{ }_{s}\right)$ is used to compare the performance of the GDCSM to stepper motor models like I, III\&V.

10RPM GDCSM has 120 steps per revolution which provides $3^{\circ}$ Degrees per step at $40 \mathrm{~ms}$ of step angle delay (A) time. At $40 \mathrm{~ms}$ of $\mathbf{A}$, it has $0.0 \%$ of $\mathbf{R E}{ }_{\mathrm{S}}$ with maximum Change in consuming voltage tolerance $(\Delta)$ of $-0.39 \%$ at 1RPM. 10RPM GDCSM behaves like stepper motor up to 2 RPM only.
30RPM GDCSM has 55 steps per revolution which provides $6.55^{\circ}$ Degrees per step at $25 \mathrm{~ms}$ of $\boldsymbol{A}$. At $1 \mathrm{RPM}$, it has $40 \mathrm{~ms}$ of $\boldsymbol{A}$ and $0.1 \%$ of $\mathbf{R E}_{\mathrm{s}}$ with maximum value of $\Delta$ is $0.29 \%$ during horizontal movement and it has $1.9 \%$ of $\mathbf{R E}_{\mathrm{S}}$ with maximum value of $\Delta$ is $-0.39 \%$ during vertical movement. If its value of $\Delta$ controlled during vertical movement is less than or equal to $-0.29 \%$ 30RPM GDCSM behaves like stepper motor during vertical and horizontal movement at $1 \mathrm{RPM}$. Controlling $\Delta$ value to maximum reduces the $\mathbf{R E}_{\mathrm{S}}$ value. 30RPM GDCSM behaves like stepper motor at $2 \mathrm{RPM}$ when its vertical movement of $\mathbf{R} \mathbf{E}_{\mathrm{s}}$ value is less than acceptable slippage degree tolerance.

GDCSM behaves like stepper motor at low-speed conditions up to 2RPM only. GDCSM is used in low-speed applications like solar tracking systems. GDCSM can be operable at very low step angle delay time (A) (i.e., less than $1^{\circ}$ angular position change). GDCSM is used in low speed and holding a vertical angular position application where stepper motors like 28BYJ-48 or STP-43d1027-01 are unable to control vertical holding position. Minimization of $\mathbf{R E}_{S}$ value as the speed is increased using step delay time (D) switching parameter in our future scope. Analyzing various load conditions of GDCSM will be further investigated.

Author contributions 1. Venkatarao Dadi: Lead the roles in Conceptualization, Investigation, Methodology, Software, Validation, Writing - original draft, Writing - review \& editing. 2. Swapna Peravali: Lead the roles in Validation, Writing - review \& editing. 3. Rambabu Busi: Supporting Review only.

Declarations

Conflict of interest On behalf of all authors, the corresponding author states that there is no conflict of interest.

Open Access This article is licensed under a Creative Commons Attribution 4.0 International License, which permits use, sharing, adaptation, distribution and reproduction in any medium or format, as long as you give appropriate credit to the original author(s) and the source, provide a link to the Creative Commons licence, and indicate if changes were made. The images or other third party material in this article are included in the article's Creative Commons licence, unless indicated otherwise in a credit line to the material. If material is not included in the article's Creative Commons licence and your intended use is not permitted by statutory regulation or exceeds the permitted use, you will need to obtain permission directly from the copyright holder. To view a copy of this licence, visit http://creativecommons. org/licenses/by/4.0/.

\section{References}

1. Viaene JD et al (2018) Load angle estimation for dynamic stepping motor motion applications. Mechatronics. https://doi.org/ 10.1016/j.mechatronics.2018.06.017 
2. Divakar A et al (2016) A Study on DC motor operations and speed control using microcontroller. Int J Adv Res Electr Electron Instrum Eng. https://doi.org/10.15662/IJAREEIE.2016.0504038

3. Hameed HQ et al (2016) Design of a PC-based DC motor speed controller. Diyala J Eng Sci 9(2):1-14. https://doi.org/10.24237/ djes.2016.09204

4. Raza KM, Kamil M et al (2016) Speed control of DC motor by using PWM. Int J Adv Res Comput Commun Eng 5(4):307-309. https://doi.org/10.17148/IJARCCE.2016.5478

5. Hassan AA et al (2018) Comparative study for DC motor speed control using PID controller. Int J Eng Technol 9(6):4181-4192. https://doi.org/10.21817/ijet/2017/v9i6/170906069

6. Syukriyadin S et al (2018) Permanent magnet DC motor control by using arduino and motor drive module BTS7960. IOP Mater Sci Eng. https://doi.org/10.1088/1757-899X/352/1/012023

7. Pinto VH (2021) Model of a DC motor with worm gearbox. Controlo. https://doi.org/10.1007/978-3-030-58653-9_61

8. Verstraten T et al (2015) Modeling and design of geared DC motors for energy efficiency: comparison between theory and experiments. Mechatronics. https://doi.org/10.1016/j.mecha tronics.2015.07.004

9. Bai W et al (2018) Dynamic characteristics of motor-gear system under load saltations and voltage transients. Mech Syst Signal Process. https://doi.org/10.1016/j.ymssp.2017.07.039

10. Massey $S$ et al (2016) Modeling, simulation and control of hybrid electric vehicle drive while minimizing energy input requirements using optimized gear. https://doi.org/10.37099/mtu.dc. etdr/133

11. Ma A et al (2020) Application of EMPC for precise position control of DC-motor system with Backlash. Control Eng Pract. https://doi.org/10.1016/j.conengprac.2020.104422

12. Maung MM et al (2018) DC motor angular position control using PID controller with friction compensation. Int J Sci Res Publ 8(11):149-155. https://doi.org/10.29322/IJSRP.8.11.2018.p8321

13. Paul $\mathrm{H}$ et al (2016) Precise Control of angular position of geared DC motors for low cost applications. Int J Innov Res Sci Eng Technol. https://doi.org/10.15680/IJIRSET.2016.0505596

14. Kataboina SK et al (2020) Multi-functional electrical vehicle for agricultural applications. J Adv Res Dyn Control Syst. https://doi. org/10.5373/JARDCS/V12I2/S202010012
15. Min S et al (2019) Efficient multi-objective optimization of gear ratios and motor torque distribution for electric vehicles with two-motor and two-speed powertrain system. Appl Energy. https://doi.org/10.1016/j.apenergy.2019.114190

16. Khatkhat AM et al (2019) Design of an Electrochemical based rain sensing (ERS) wiper system for local transport (comparison of performance of conventional Lucas wiper motor with geared DC motor). Int J Res Anal Rev. https://doi.org/10.6084/m9.doi. one.IJRAR19K3103

17. Al-Jarrah A, Salah S et al (2015) Applications of various control schemes on a four-bar linkage mechanism driven by a geared DC motor. WSEAS Trans Syst Contr 10:584-597

18. Tutunji TA et al (2015) Modeling and identification of a four-bar linkage mechanism driven by a geared DC motor. Int Rev Mech Eng. https://doi.org/10.15866/ireme.v9i3.6035

19. Ali SA et al (2017) Single link bilateral haptics control with PD controller and geared DC-motor in robotic rehabilitation technology. Int J Mech Mechatron Eng 17(05), URL 171505-4848-IJMME-IJENSOctober2017IJENS

20. Frankovsky P et al (2017) Modeling of two-wheeled self-balancing robot driven by DC gear motors. Int J of Appl Mech Eng. https://doi.org/10.1515/ijame-2017-0046

21. Wei LJ et al (2016) Investigation on MDOF bilateral teleoperation control system using geared DC-motor. Mod Appl Sci. https:// doi.org/10.5539/mas.v10n11p54

22. Dadi V, Peravali $S$ et al (2020) Optimization of light-dependent resistor sensor for the application of solar energy tracking system. SN Appl Sci. https://doi.org/10.1007/s42452-020-03293-x

23. Kecskés I et al (2018) Gear efficiency modeling in a simulation model of a DC gearmotor. In: 18th IEEE International symposium on computational intelligence and informatics . https://doi.org/ 10.1109/EIConRus.2017.7910693

24. Wahyu SA et al (2019) DC motor simulation transfer function estimation: case study Proteus Ve .7. Mat Sci Eng. https://doi. org/10.1088/1757-899X/674/1/012040)

Publisher's Note Springer Nature remains neutral with regard to jurisdictional claims in published maps and institutional affiliations. 